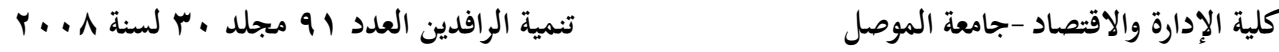

$$
\begin{aligned}
& \text { ص ص[rrA-rrr] }
\end{aligned}
$$

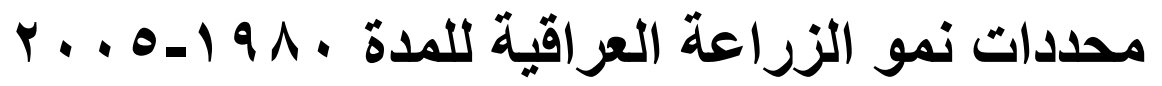

$$
\begin{aligned}
& \text { زويد فتحي عبد } \\
& \text { مدرس مساعد - قسم الإقتصاد الزراعي فيد } \\
& \text { الدكتور قيس ناظم غزال } \\
& \text { استاذ مساعد- قسم الإقتصاد الزراعي }
\end{aligned}
$$

كلية الزراعة والغابات -جامعة الموصل

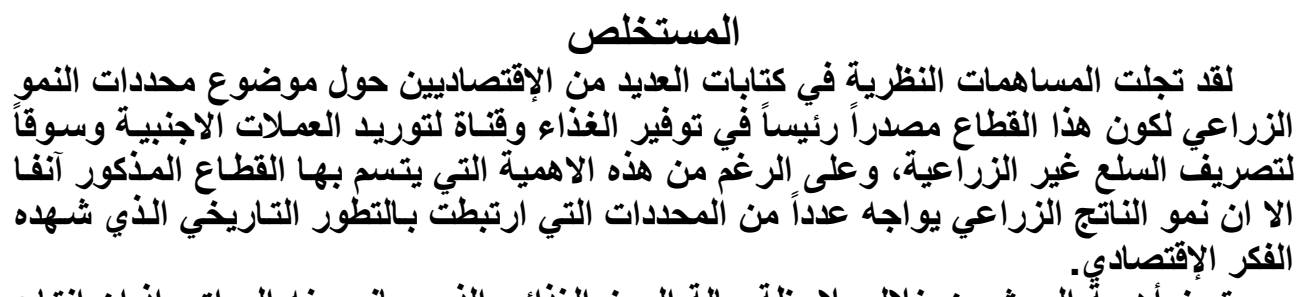

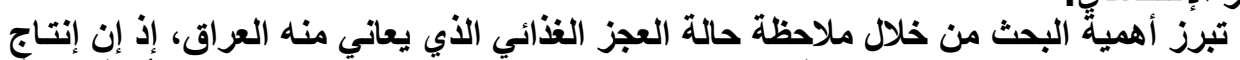

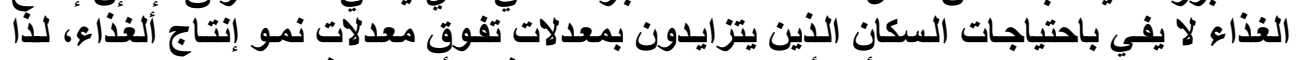

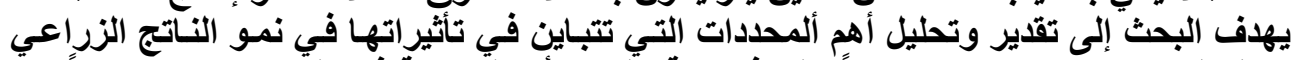

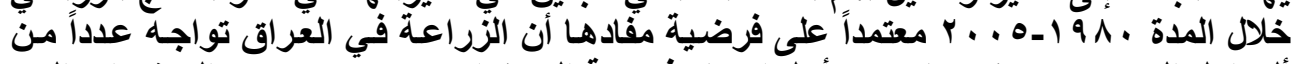

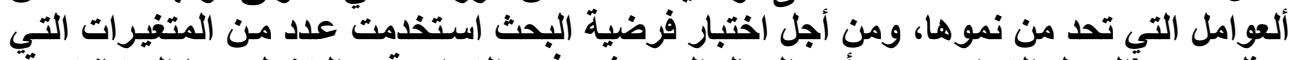

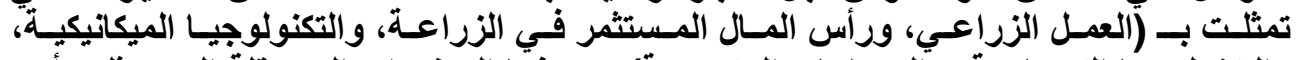

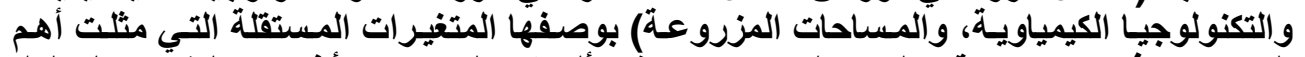

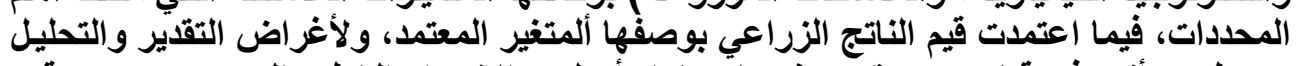

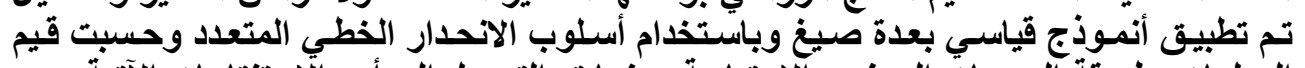

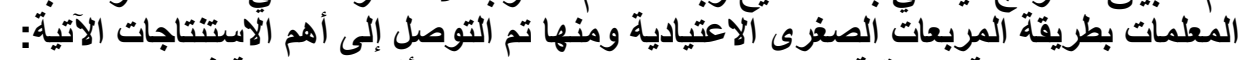

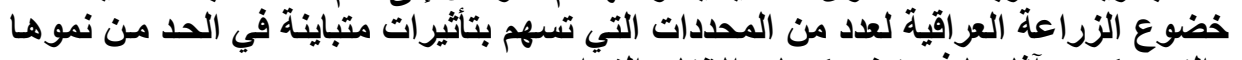
والتي عكست آثار ها في تلني كميات الانتاج الزئ الزراعي.

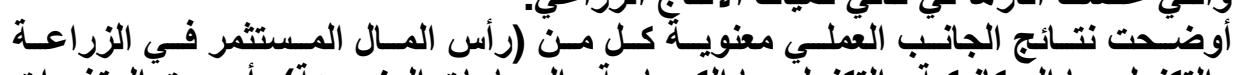

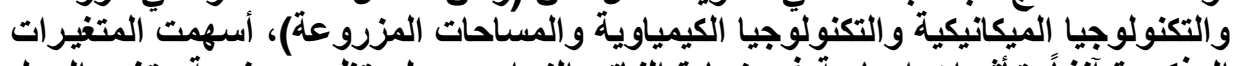

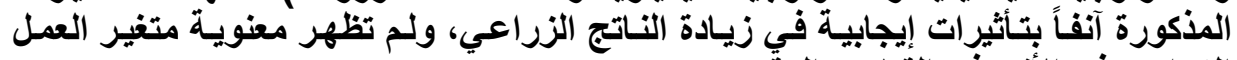

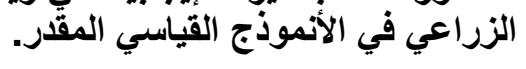

\title{
Determinants of I raqi Agriculture Growth for the Period 1980-2005
}

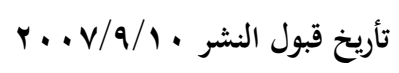

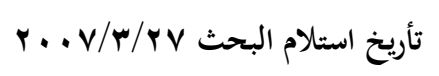


Kays Nadhim Ghazal (PhD)

Assistant Professor

Department of Economic Agriculture

University of Mosul

\author{
Zweid Fathi Abed \\ Assistant Lecturer \\ Department of Economic Agriculture \\ University of Mosul
}

\begin{abstract}
The theoretical contributions in many the economic literature on determinants of agricultural growth stated that agricultural sector is the main source of providing food and foreign currency in addition to being a market for marketing agricultural goods. Despite the importance of such sector, the agricultural growth is still facing a number of determinants that are related to the historical development of economic thought. The importance of the study lies in observing food deficiency suffered by Iraq as food production is not enough for population needs that are increasing in comparison with food production. The study aims at estimating and analyzing the main determinants that vary in their effects on the growth of agricultural production for the period 1980- 2005 depending on the hypothesis that agriculture in Iraq is facing some factors that limit its growth. To select the study hypothesis, some variables, including agricultural work, invested capital in agriculture, mechanical technology, chemical technology and the planted areas, are used as dependent variables that represented the main determinants while values of agricultural production are used as dependent variable. A standard model with various forms and multi linear regression style has been used for the purpose of estimation and analysis. The main conclusions drawn are:

Iraqi agriculture is subject to certain determinant that variously affect and limit its growth, thus reducing agricultural production.

Empirical results showed the significance of (invested capital in agriculture, mechanical technology, chemical technology and planted areas). These variables have positively increased agricultural product. Agricultural work was not significant in the estimated model.
\end{abstract}

\footnotetext{
المقدمـة

يعد النمو الإقتصادي السريع و المتو اصل من المتطلبات الرئيسة التي تقتضيها

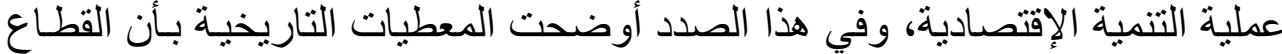

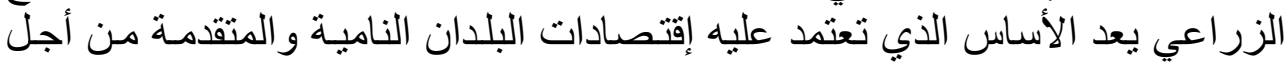

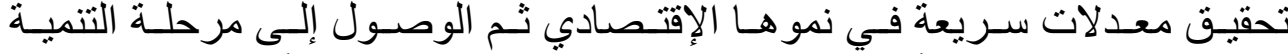

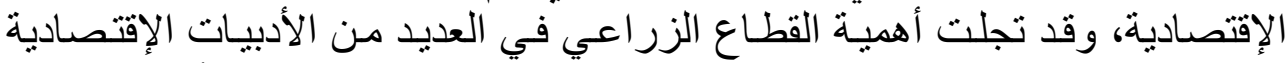

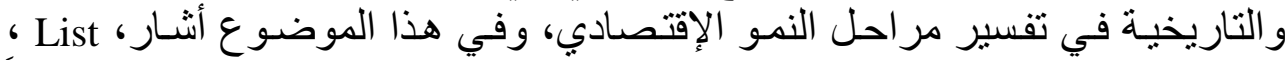

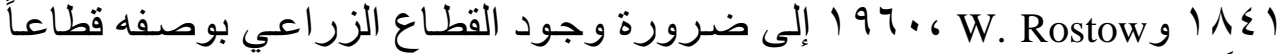

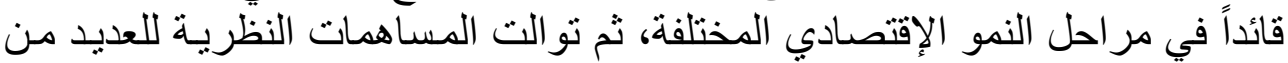

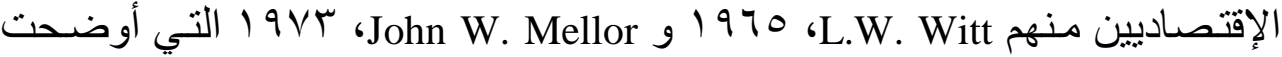

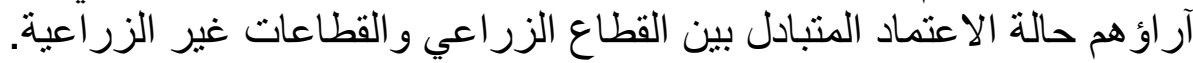

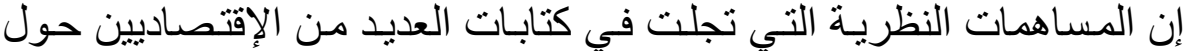

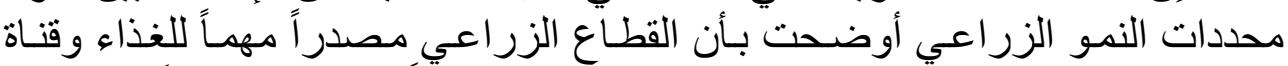

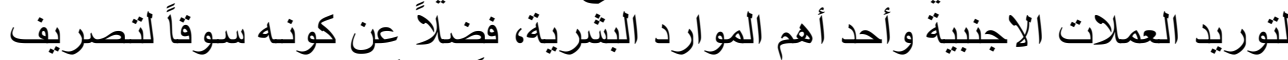

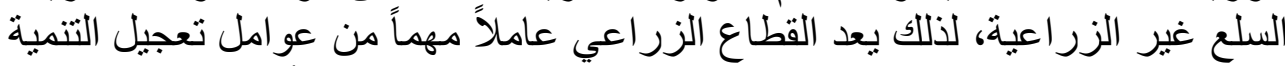

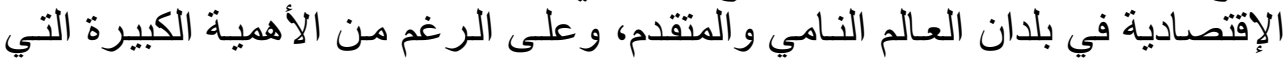




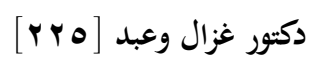

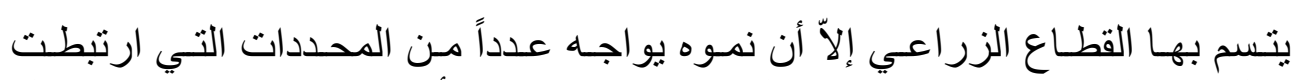

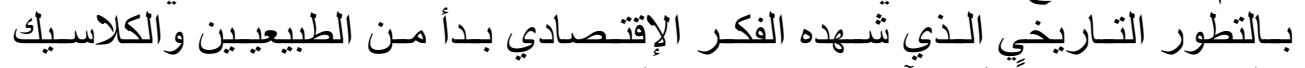

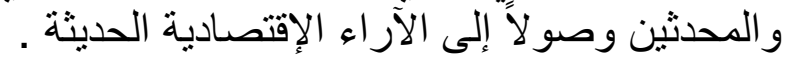

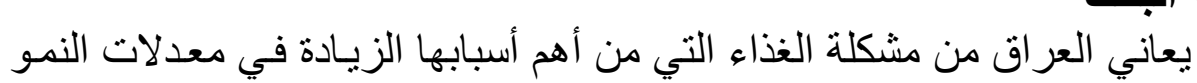

مشكلة البحث

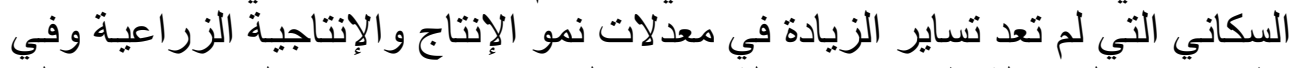

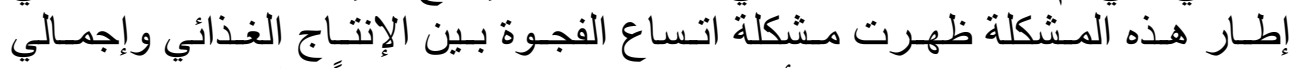

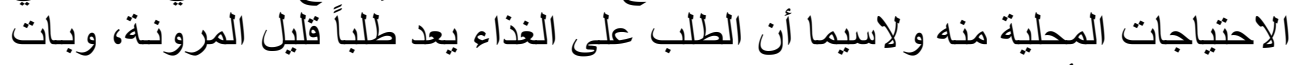

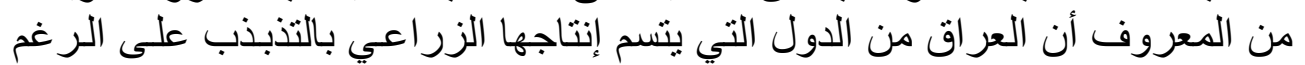

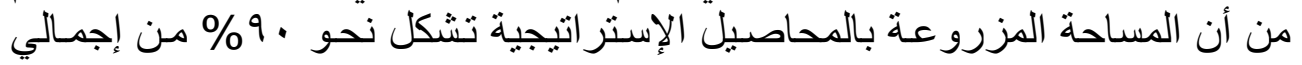

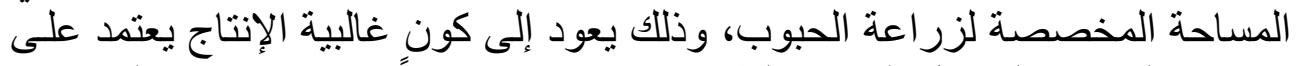

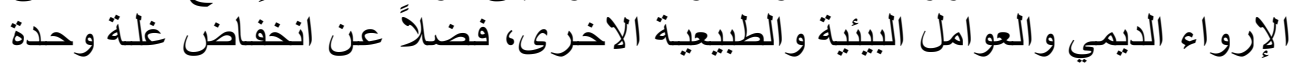

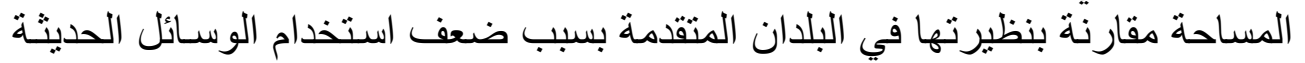

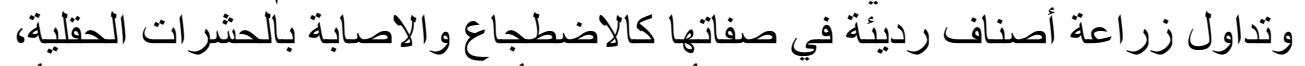

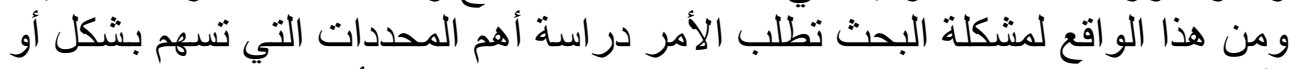
بآخر في إعاقة نمو الناتج الزراعي الذي لله مساس مبانشر بالأمن الغذائي للسكان.

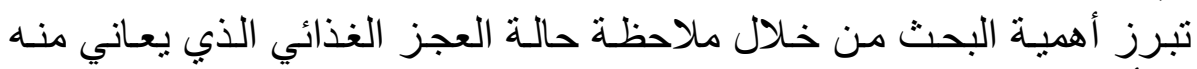

أهمية البحث

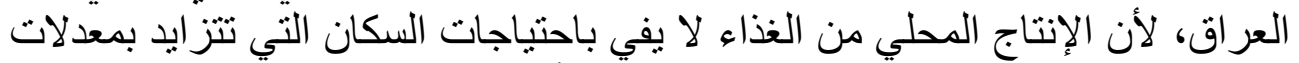

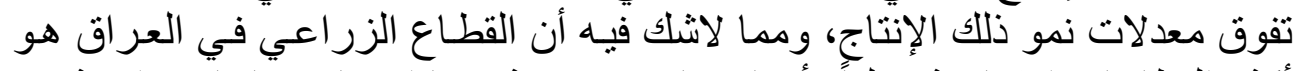

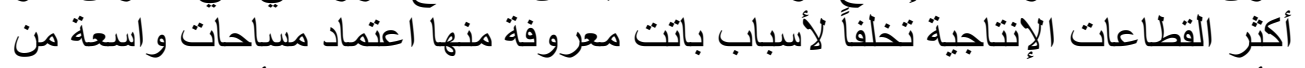

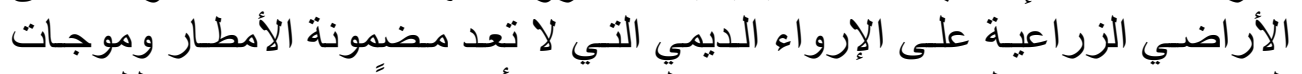

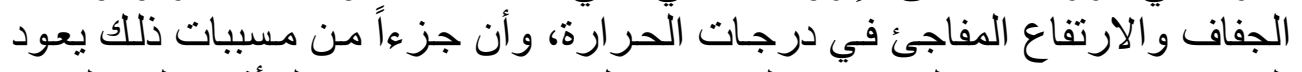

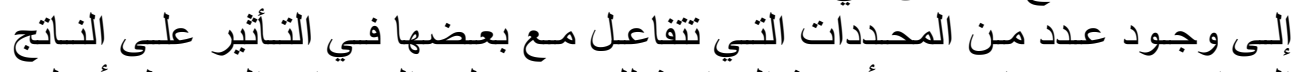

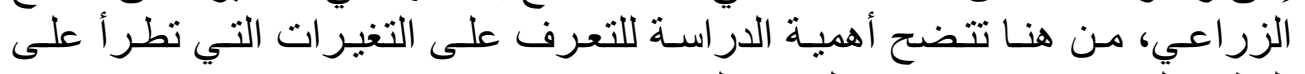
القطاع الزّر اعي و عائداته خلال مدة البحث. الزئ.

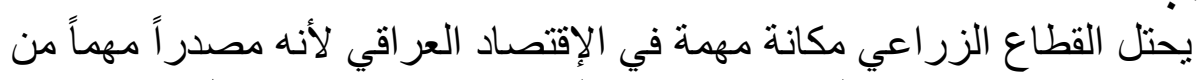
هاف البحث

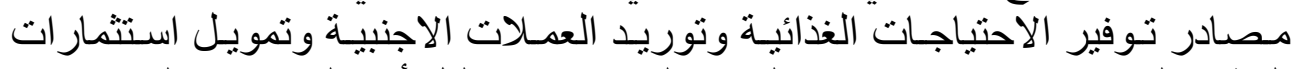

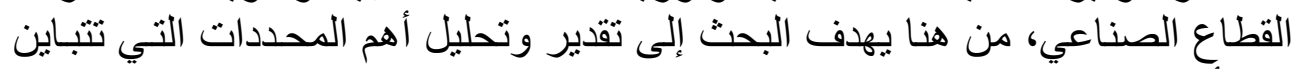

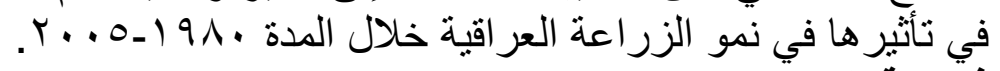




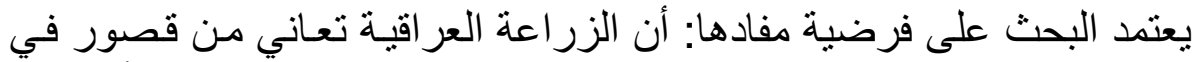

مدى مساهمتها في هيكل الإقتصاد العر اقي بفعل مجمو عة محددات يفترض بن بأنها :

$$
\begin{aligned}
& \text { العمل الزراعي. } \\
& \text { رأس المال المستثمر في الزراعة اعن. } \\
& \text { التكنولوجيا الميكانيكية. } \\
& \text { التكنولوجيا الكيمياوية. } \\
& \text { المساحات المزروعة. }
\end{aligned}
$$

\section{منهج البحث

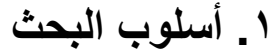

اعتمد البحث في منهجه على أسلوب الربط بين اتجاهين :

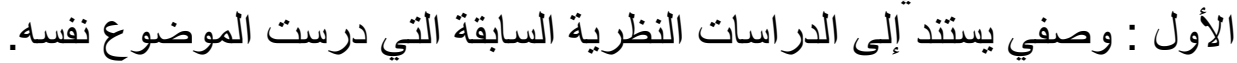

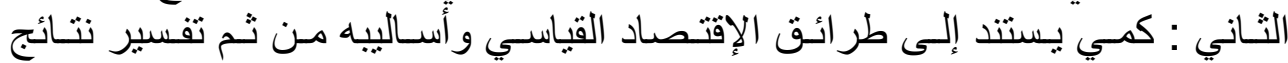

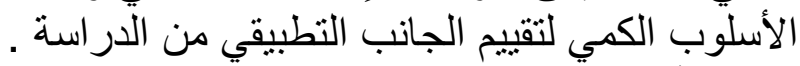

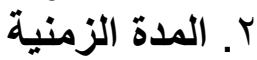

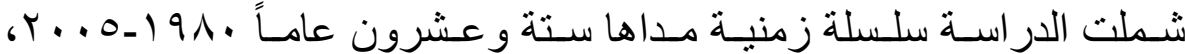

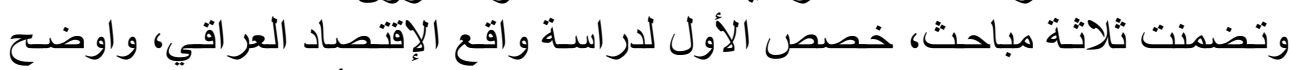

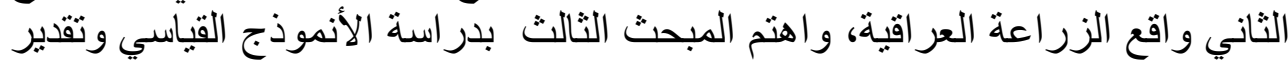

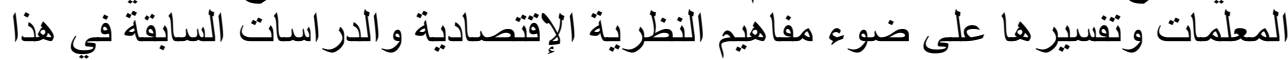
الثأن، و احتوت الدر اسة على خلاصة شملت اهم الاستتناجات و المقترحات.

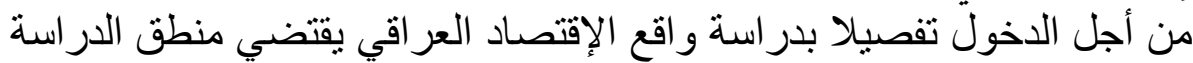

\section{واقع الإقتصاد العراقي}

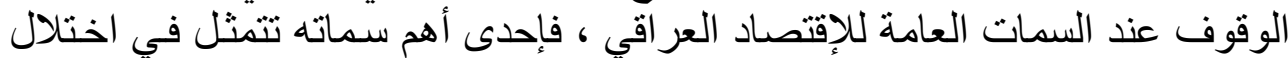

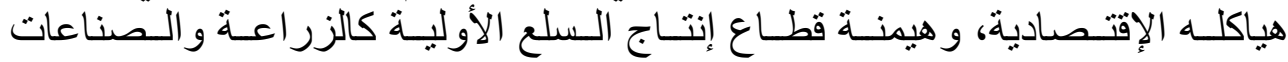

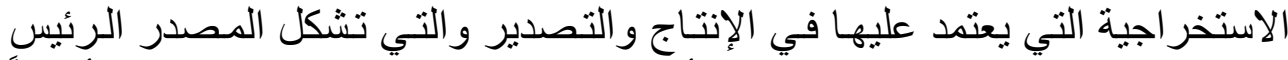

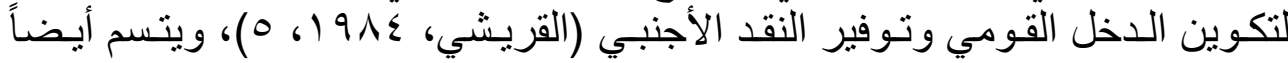

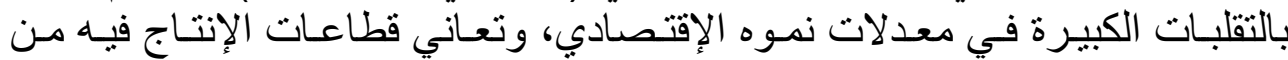

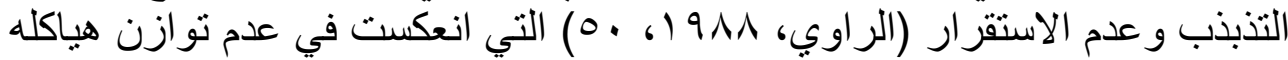

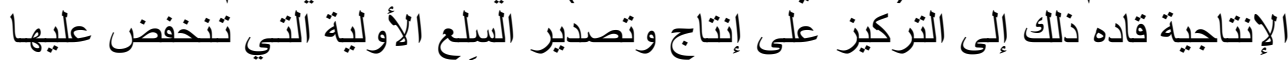

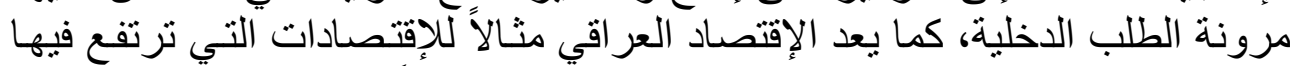

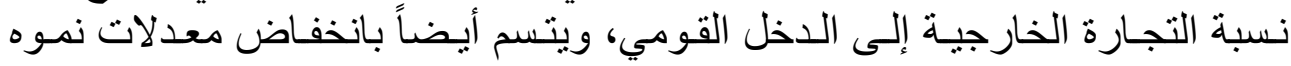

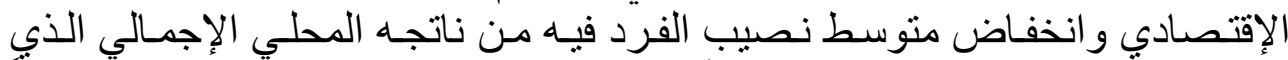

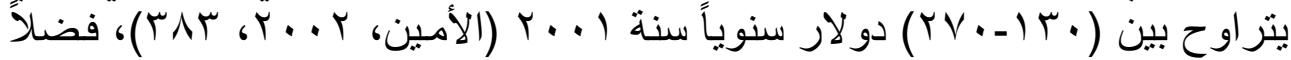

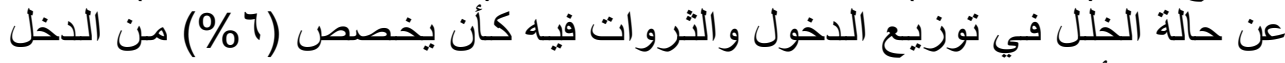

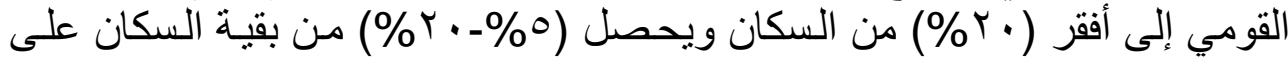




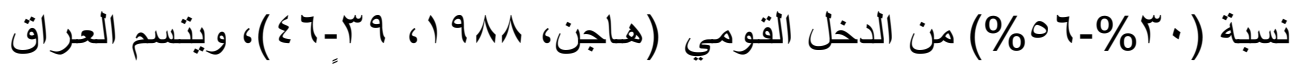

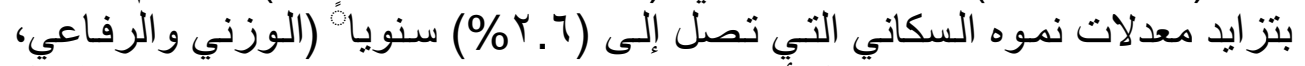

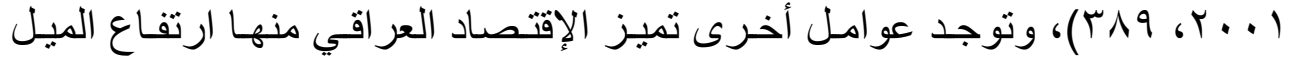

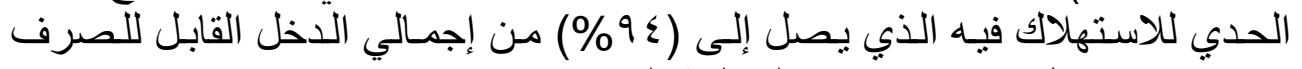

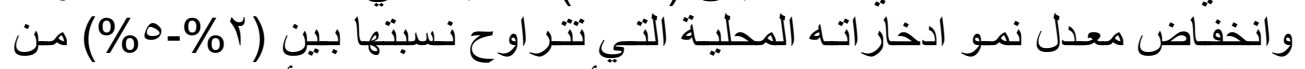

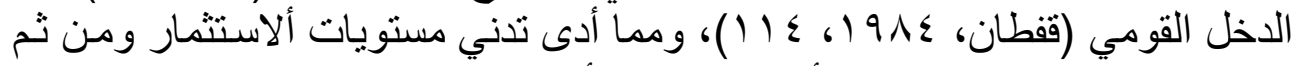

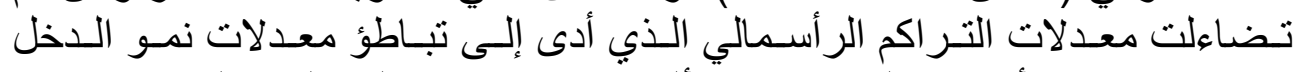

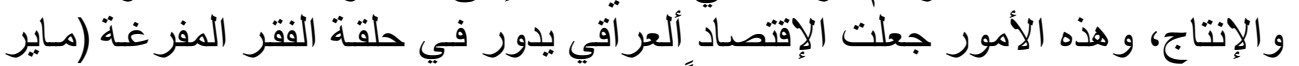

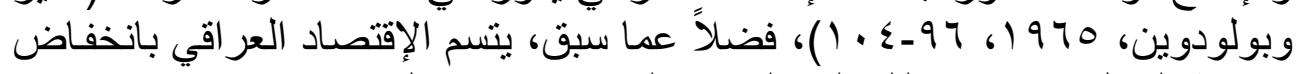

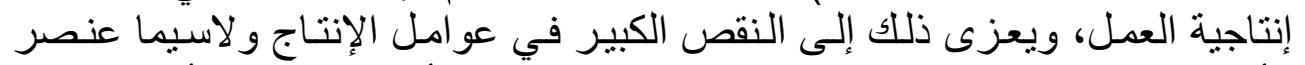

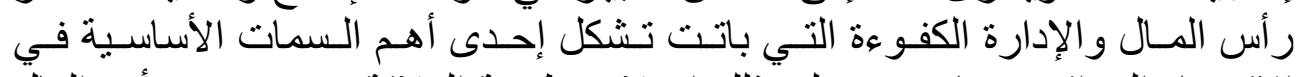

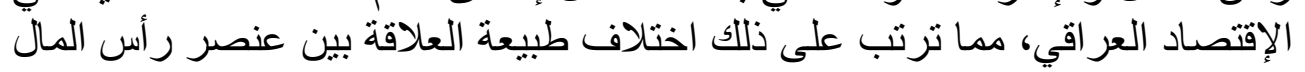

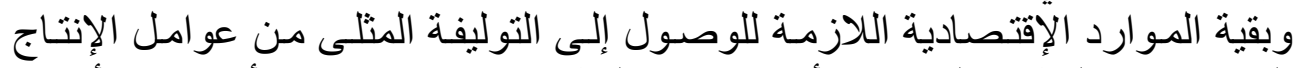

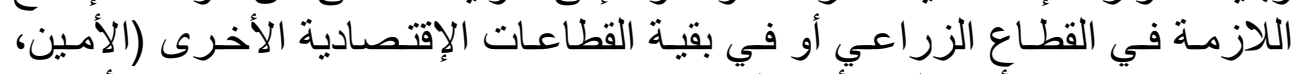

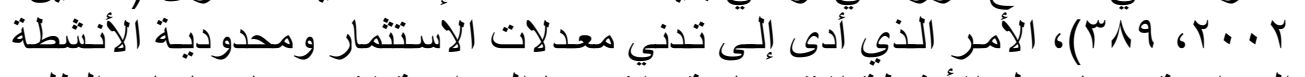

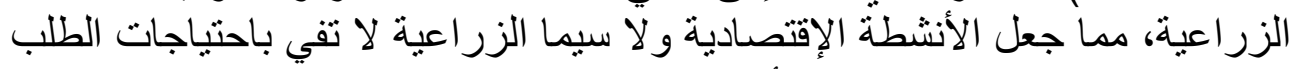

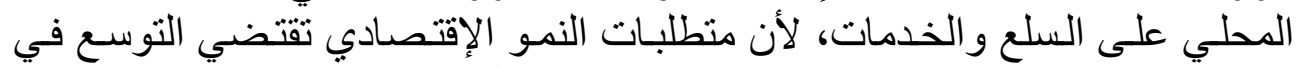

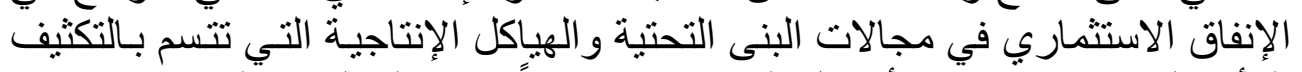

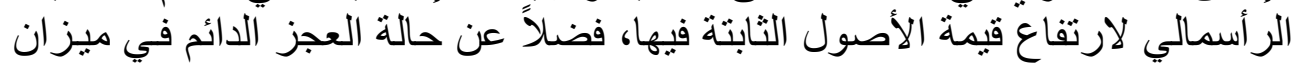

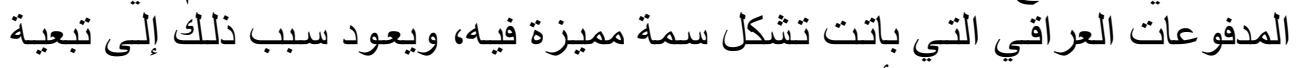

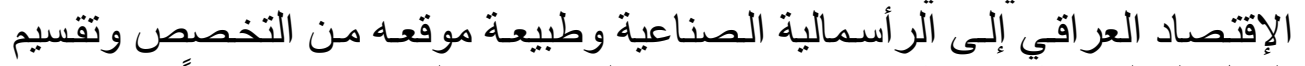

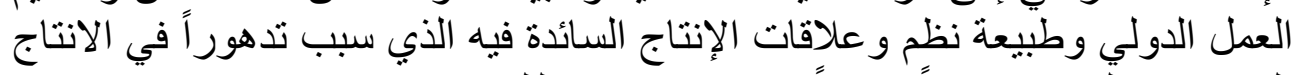

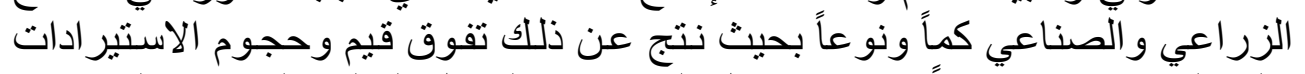

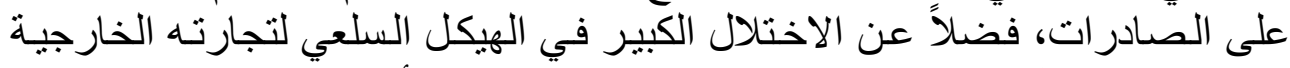

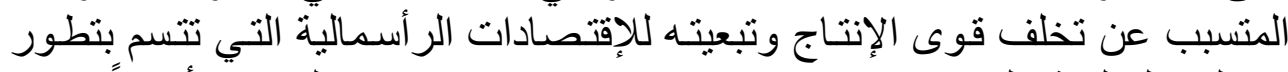

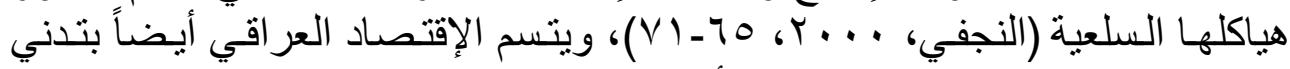

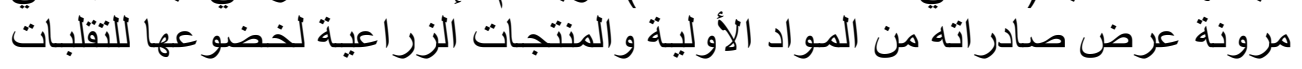

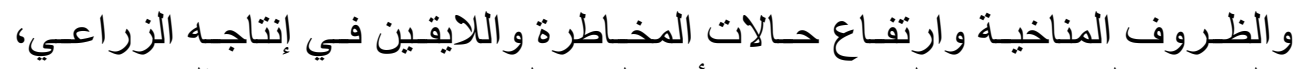

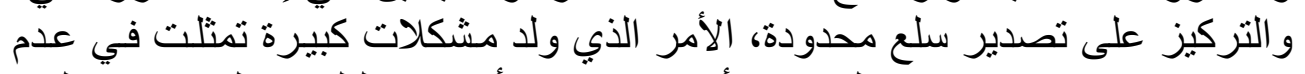

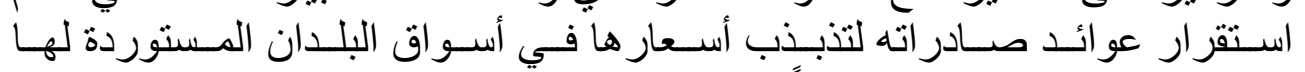

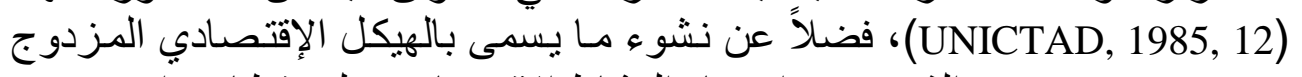
Dualism Economy

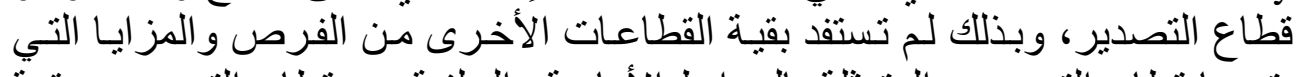

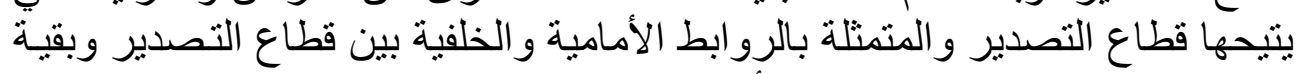

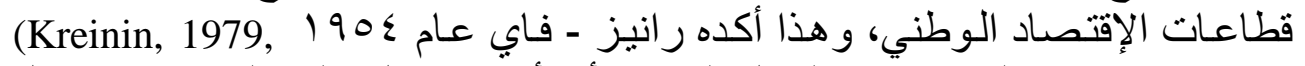

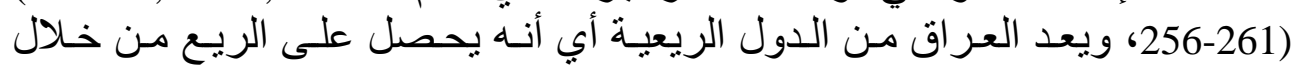




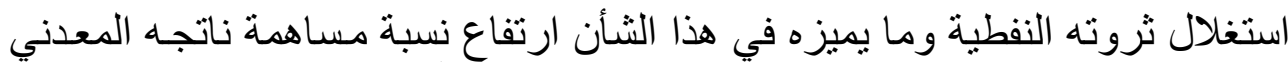

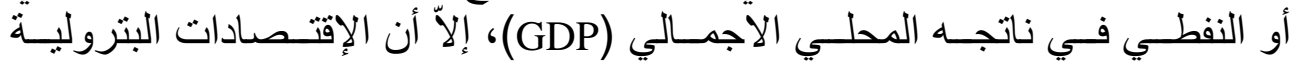

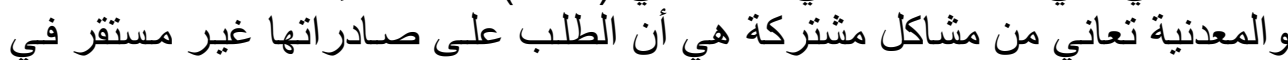

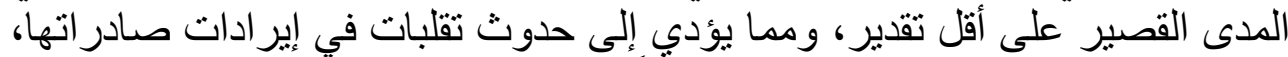

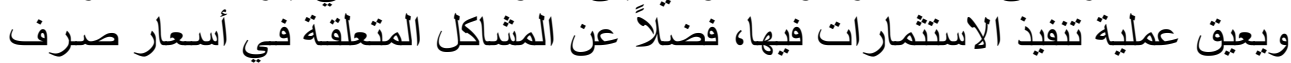

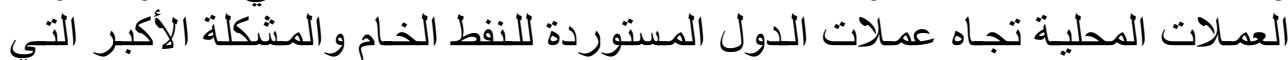

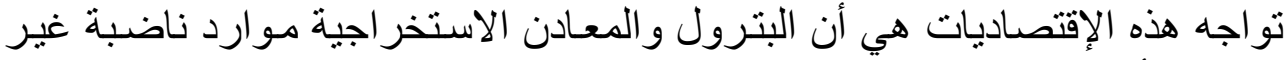

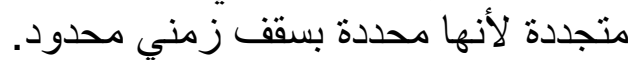

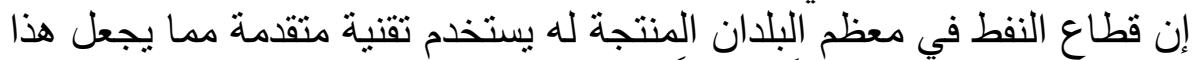

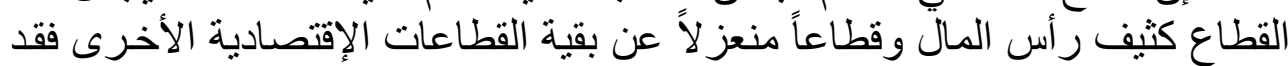

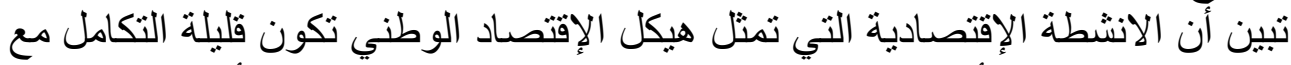

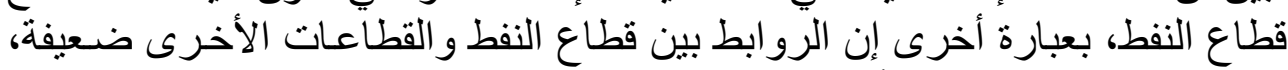

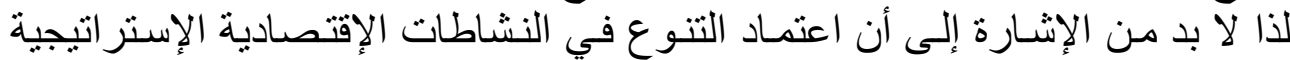

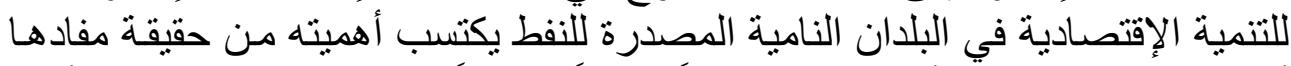

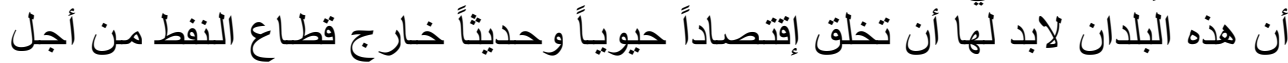

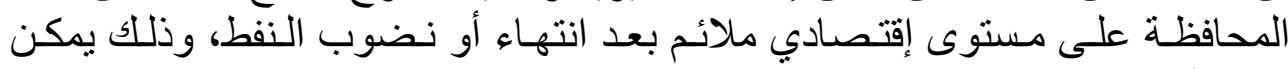

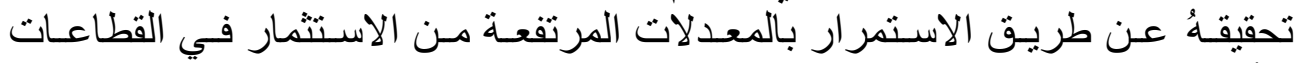

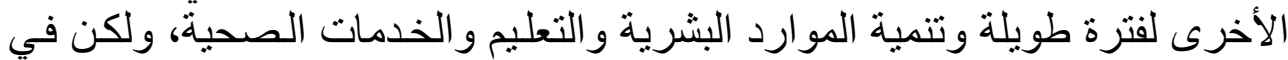

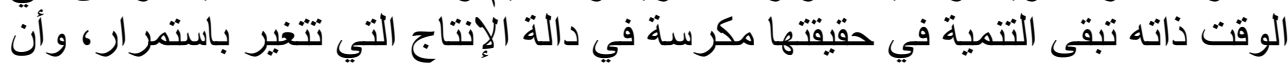

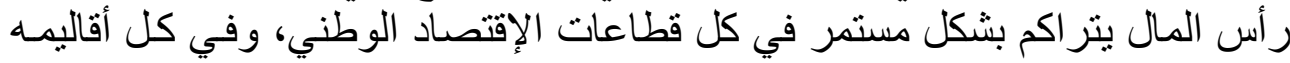

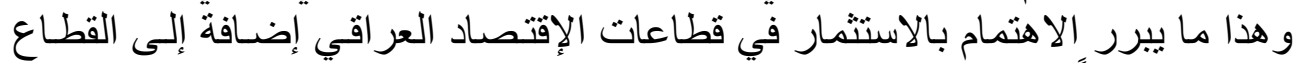

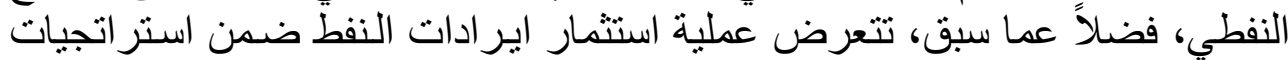

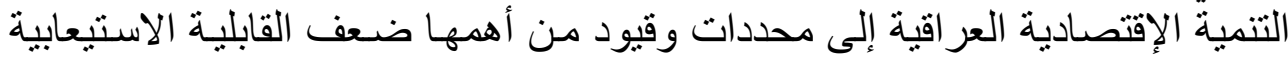

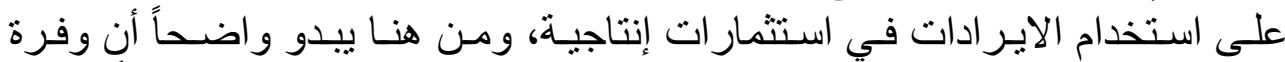

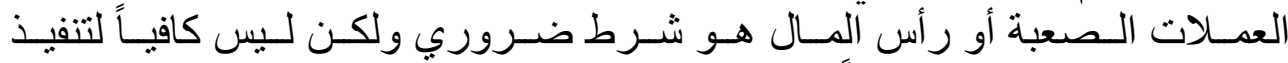

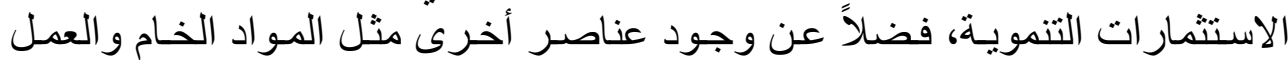

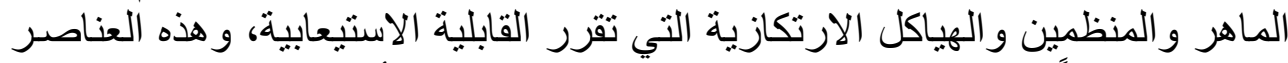

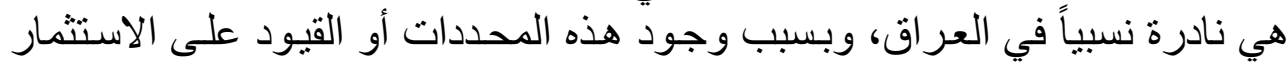
المحلي المادي لم يكن هنالك نوسع في الاستثمار في العراق.

واقع الزراعة العراقية

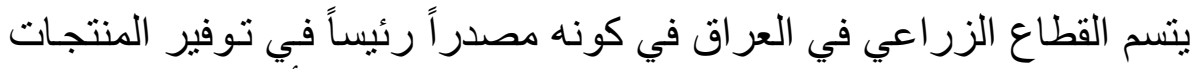

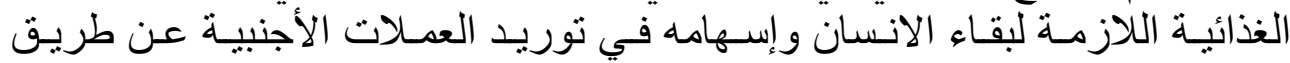

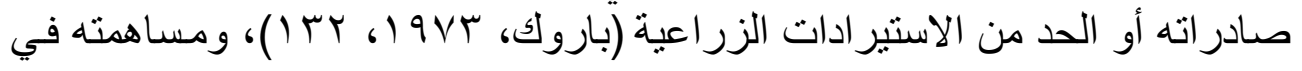




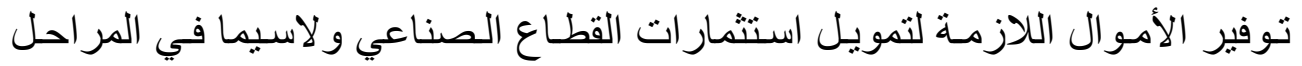

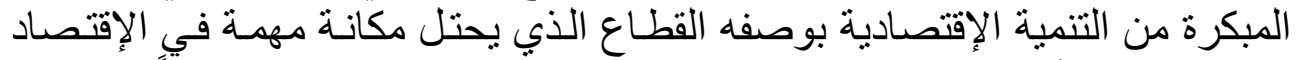

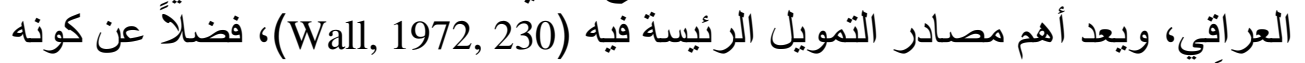

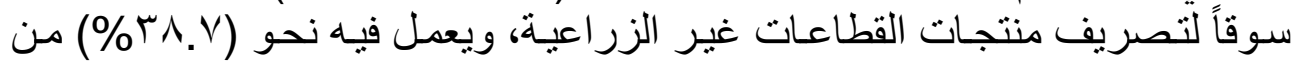

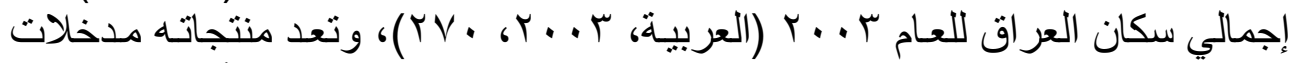

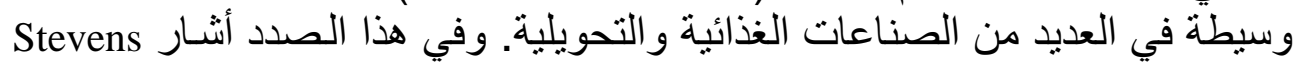

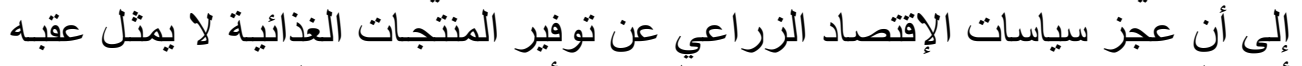

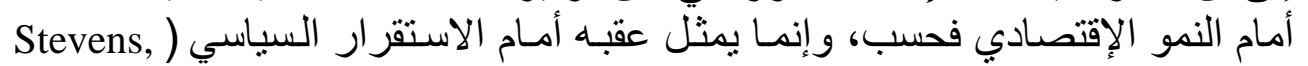

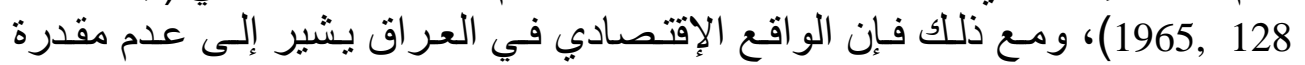

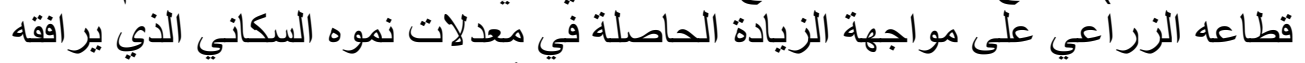

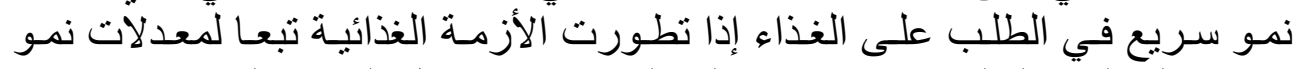

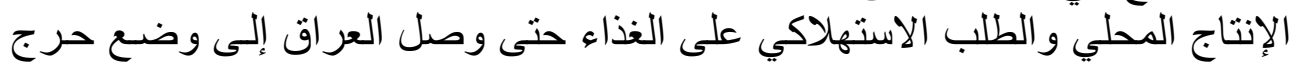

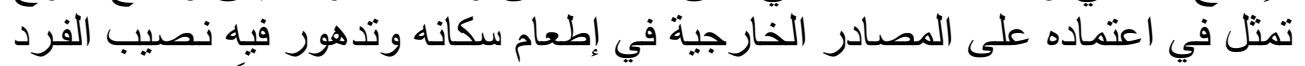

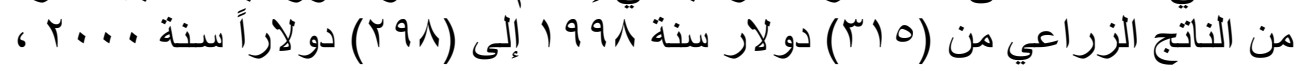

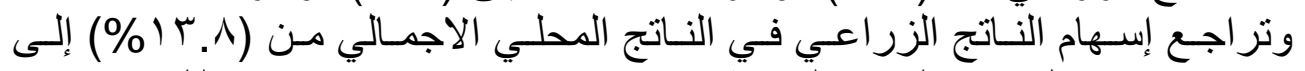

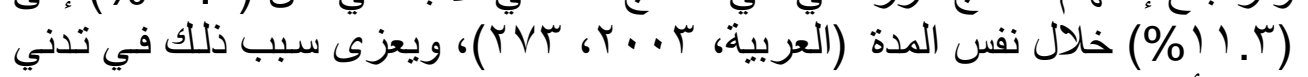

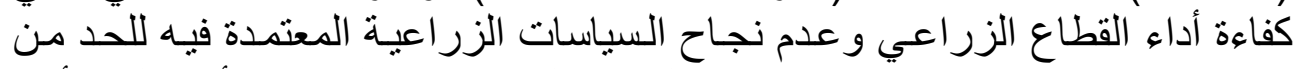

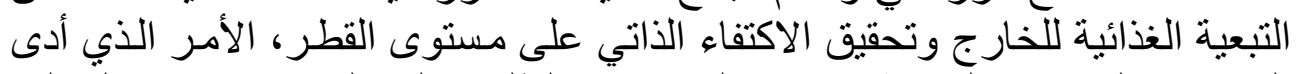

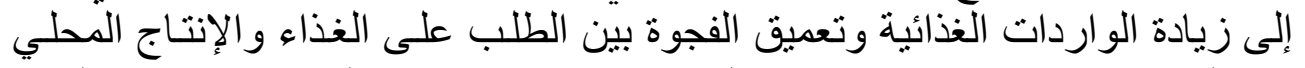

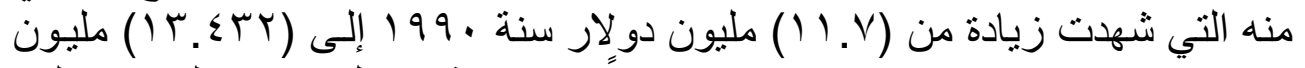

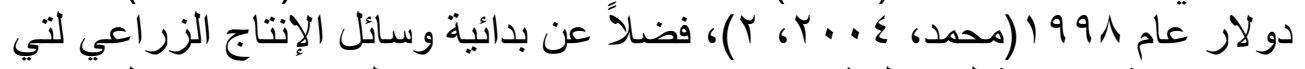

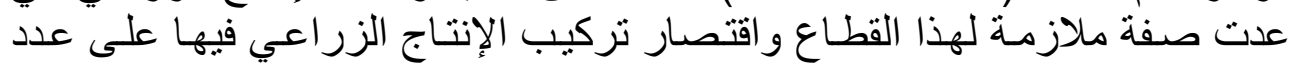

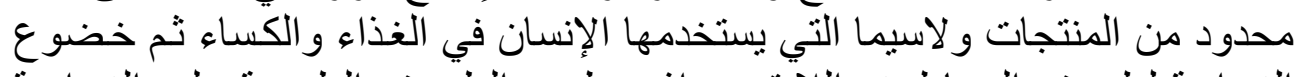

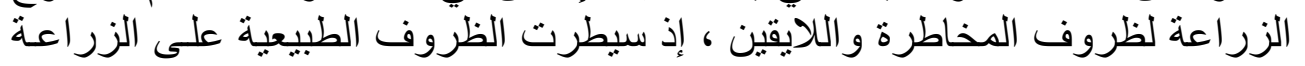

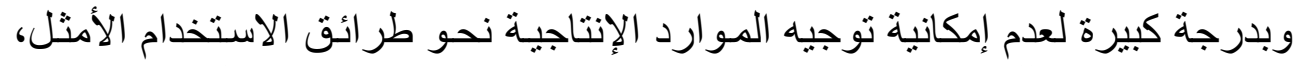

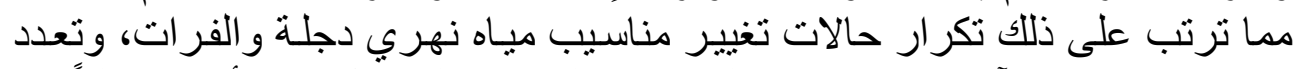

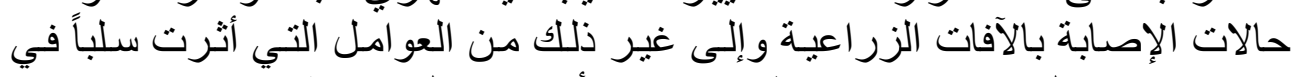

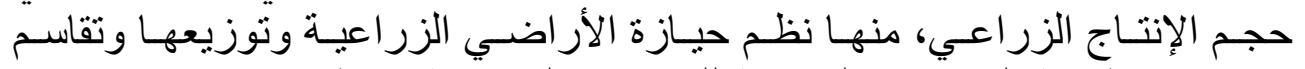

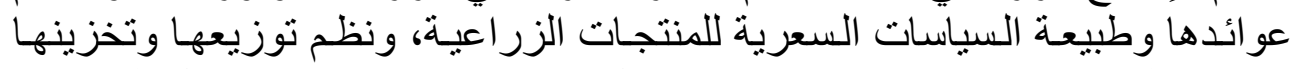

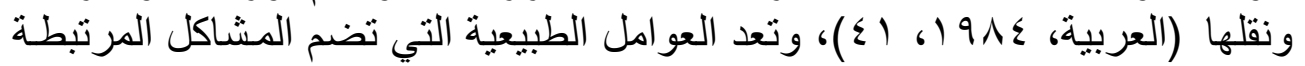

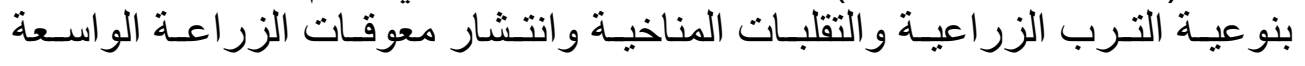

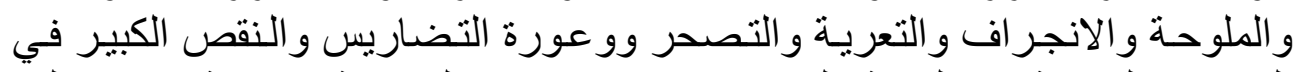

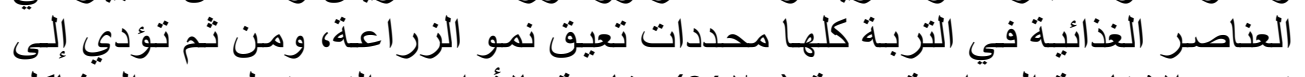

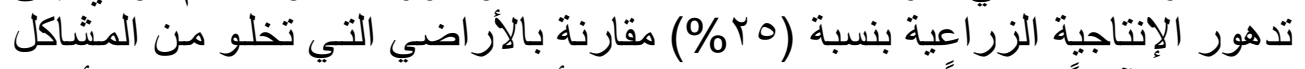

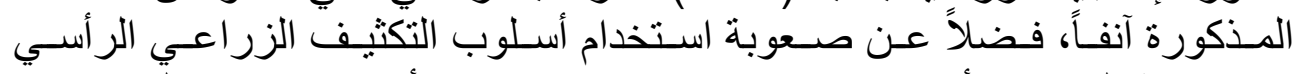

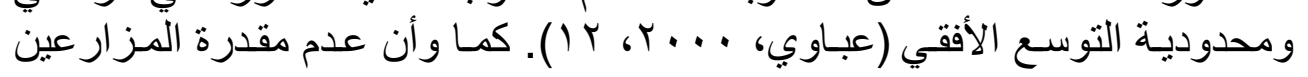


على تحقيق الاستخدام الأمثل للأر اضي الزر اعية و لاسيما في مجال استخدام الوسائل

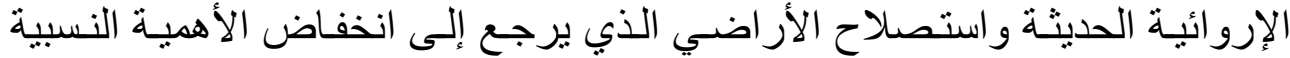

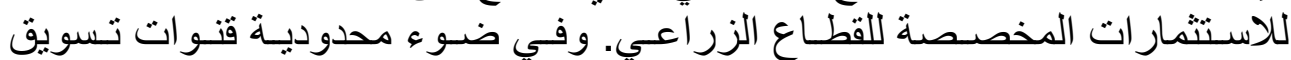

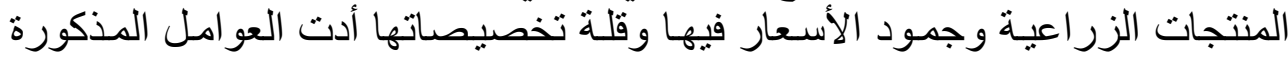

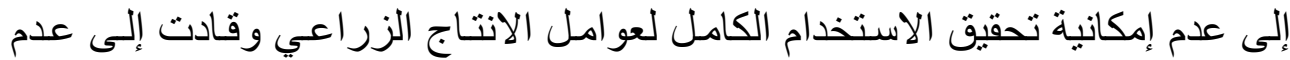

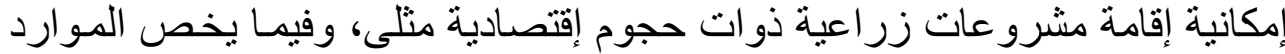

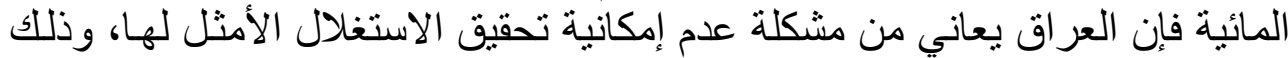

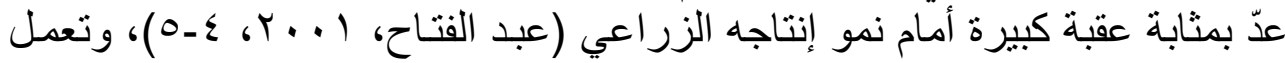

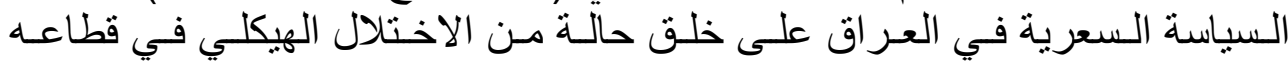

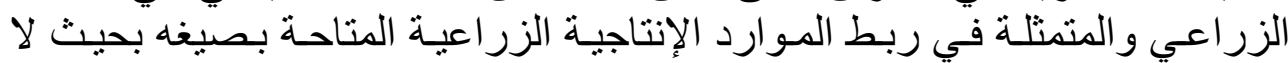

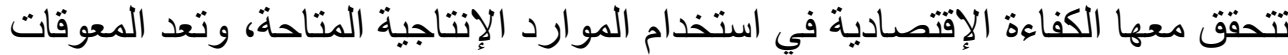

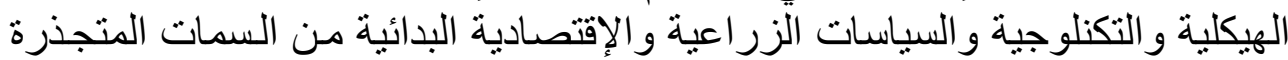

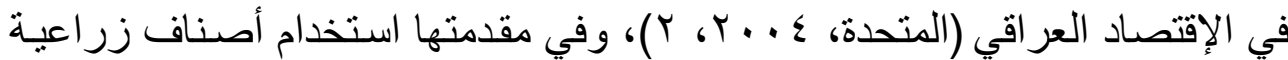

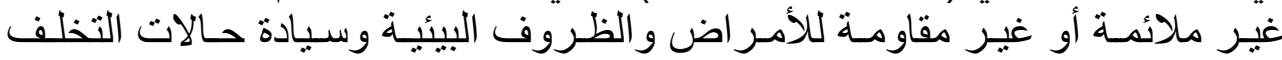

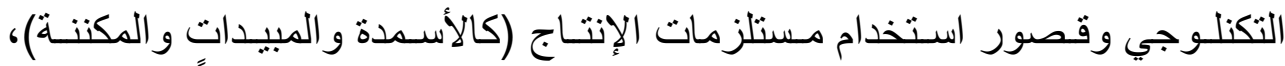

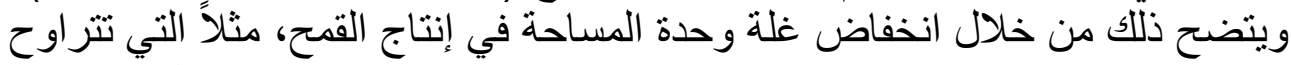

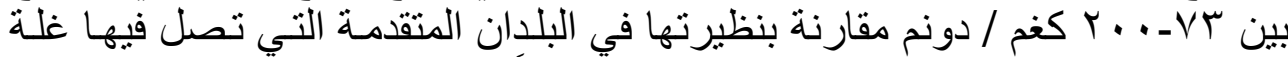

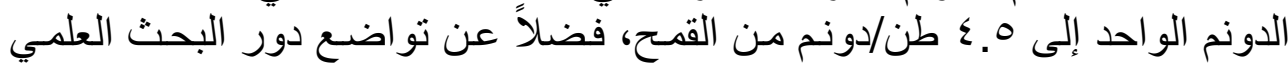

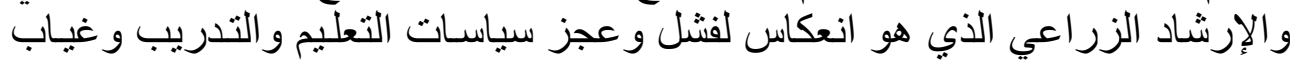
التخصص ونقص الإنصاد الكور ادر العلمية والتجهيزات الضرورية للاستثمار في مجال التعليم

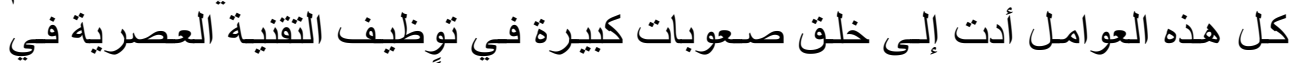

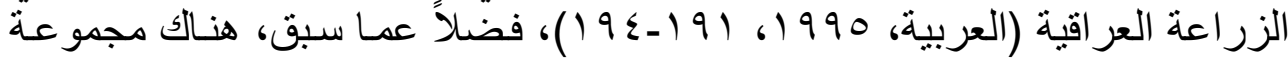

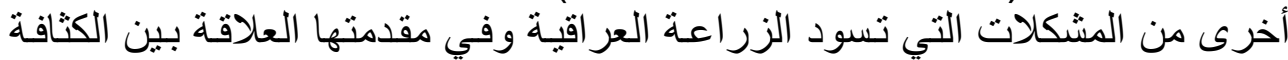

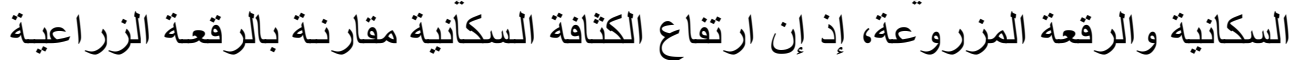

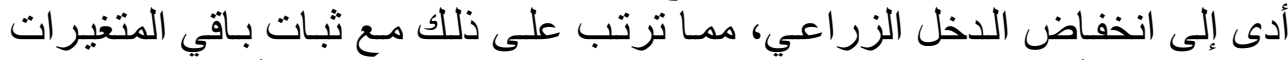

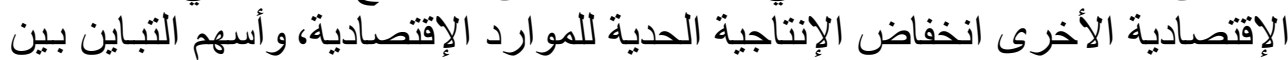

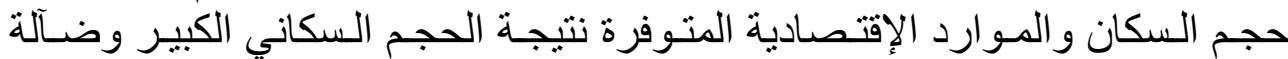
الموارد المتاحة في انخفاض نصيب الفرد من الناتج القومي وفي سيادة حالة التئة الركود

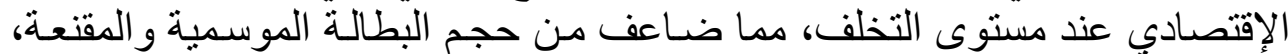

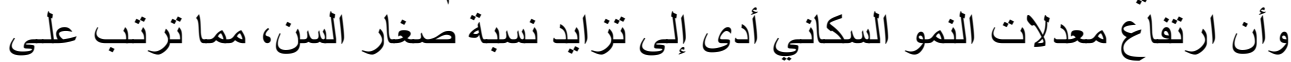

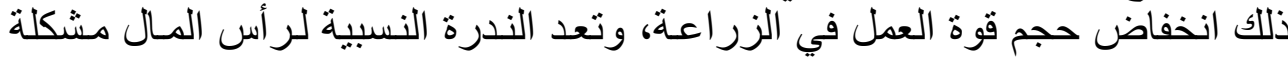

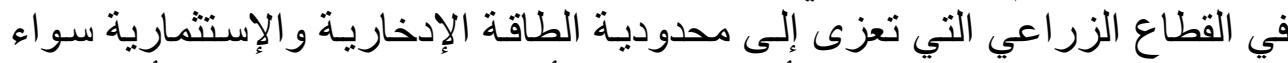

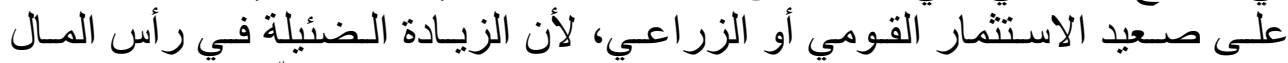

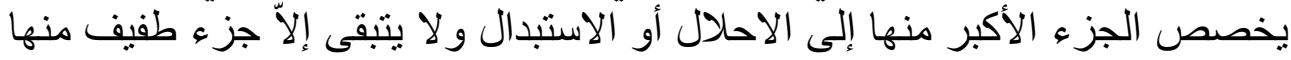

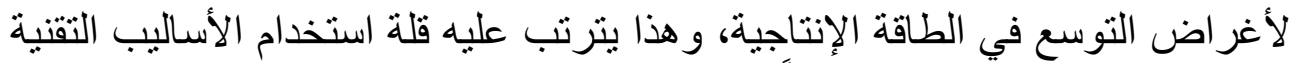
في مجال الإنتاج الزراعي، فضلاً عن أن ندرة رأس المـال تؤدي إلى تدني الهياكل 


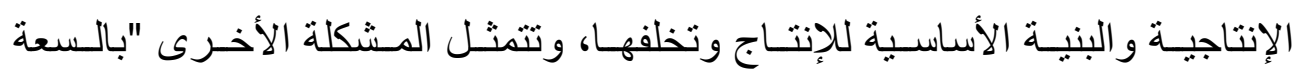

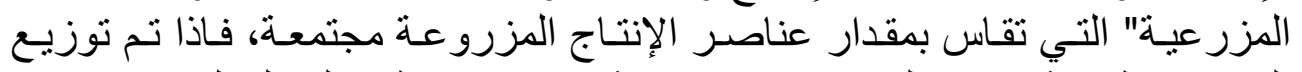

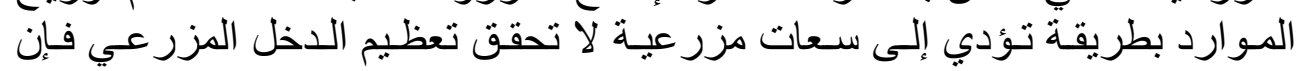

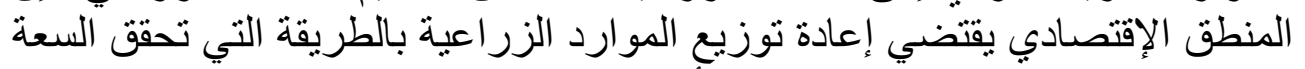

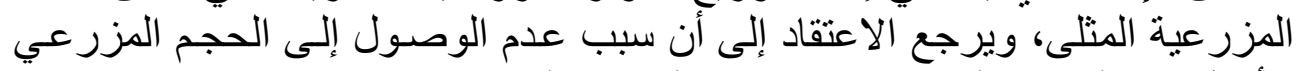

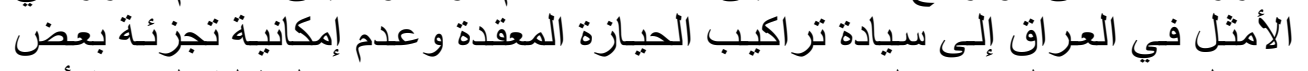

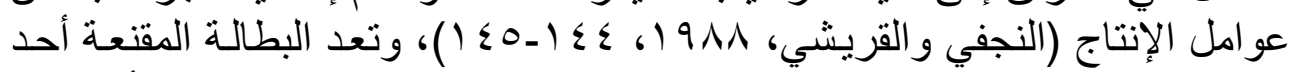

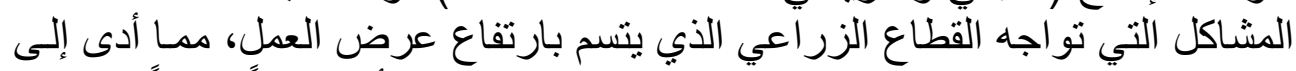

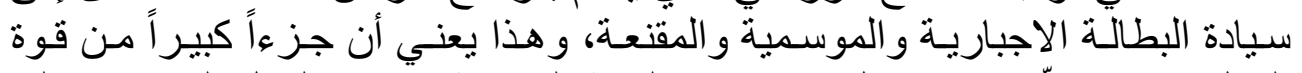

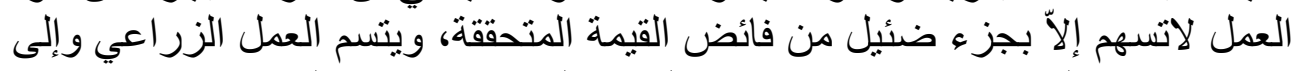

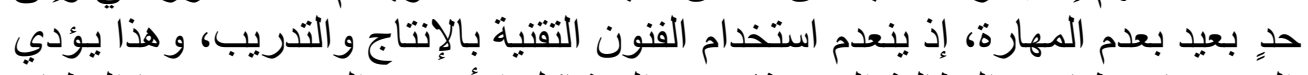

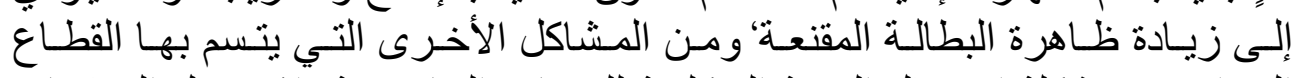

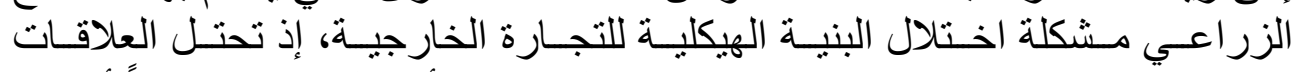

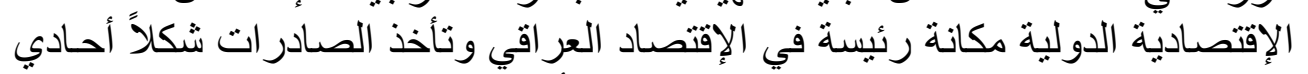

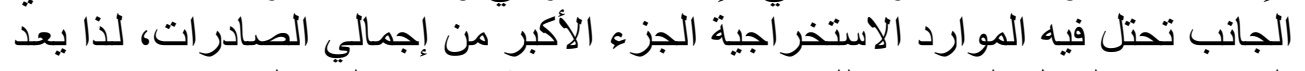

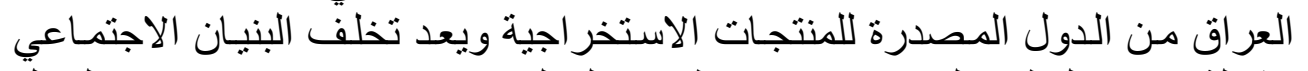

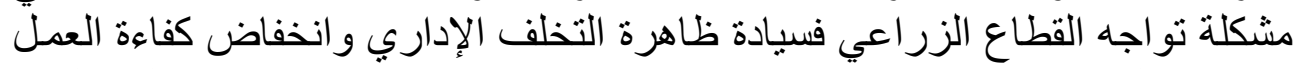

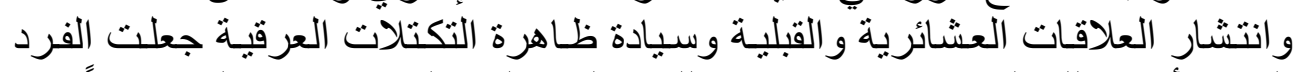

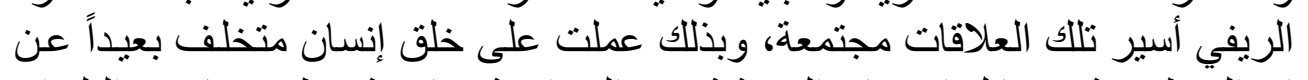

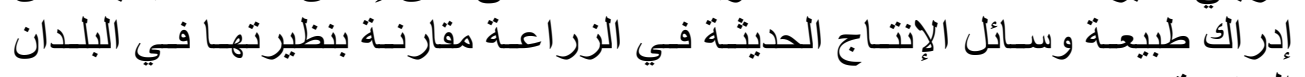
المتقدمة.

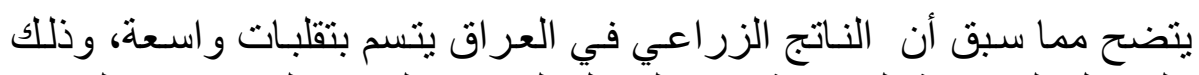

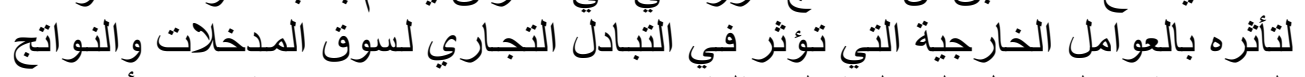

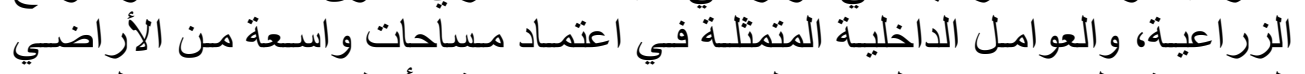

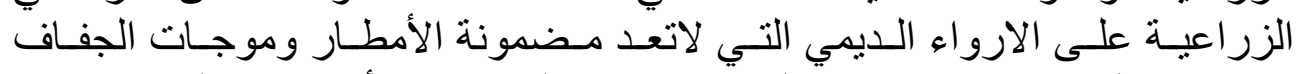

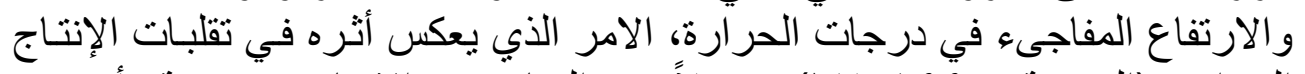

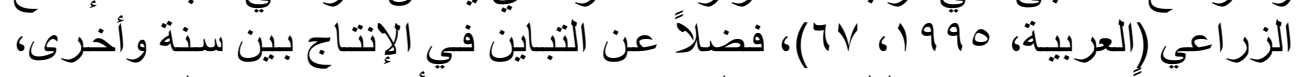

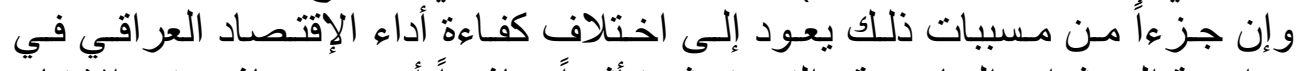

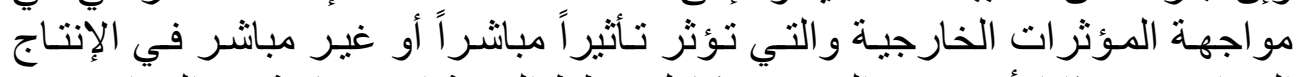

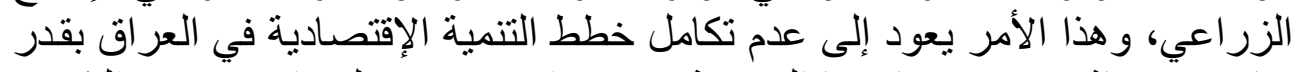

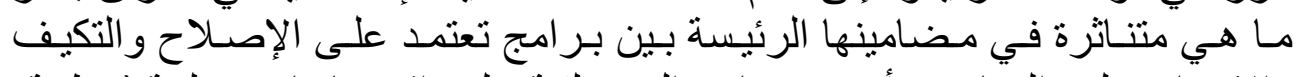

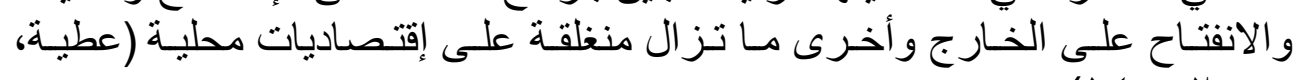

الأنموذج القياسي وتقدير المعلمات وتفسير ها اولاً. توصيف الأنموذج ونفير القياسي المستخدم في التقدير 
تعد أساليب الإقتصاد القياسي أداة رئيسة تعطي النظريـة الإقتصادية المظهر

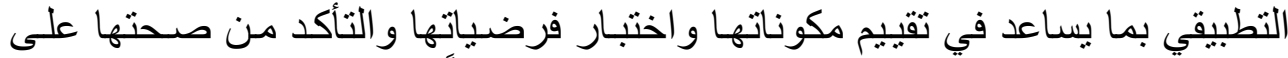

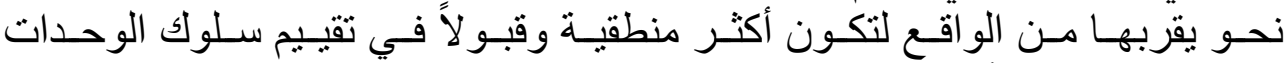

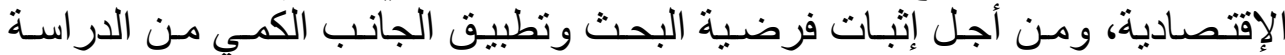

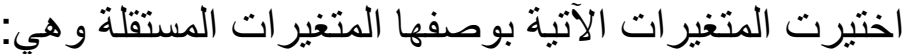

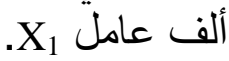

مليون دينار X

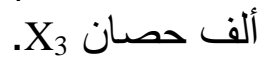

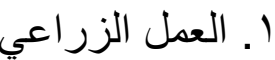

$$
\begin{aligned}
& \text { ألف طن X } \\
& \text { ألف دونم X }
\end{aligned}
$$

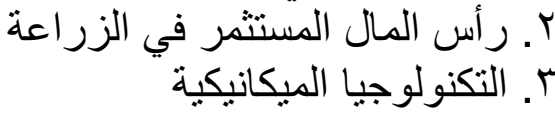

$$
\begin{aligned}
& \text { ع ـالتكنولوجيا الكيمياوية الكية } \\
& \text { ه. المساحات المزرو عة الكية }
\end{aligned}
$$

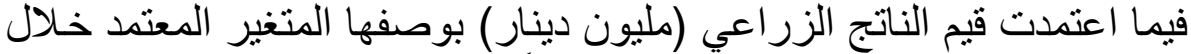

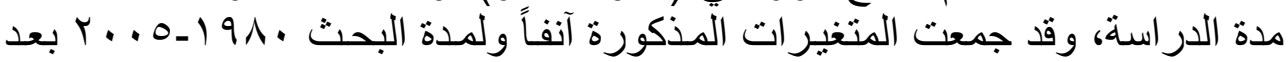

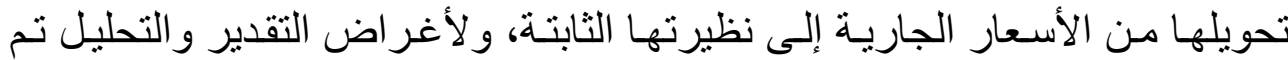

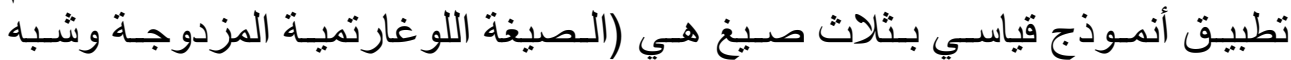

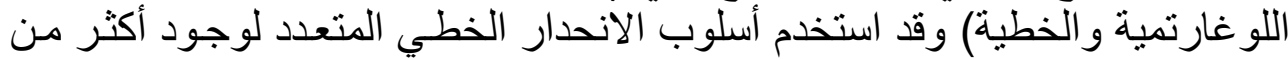

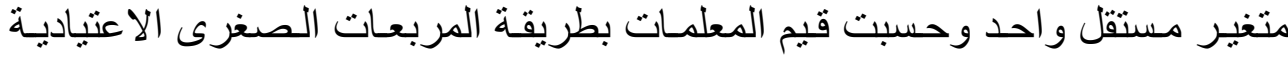

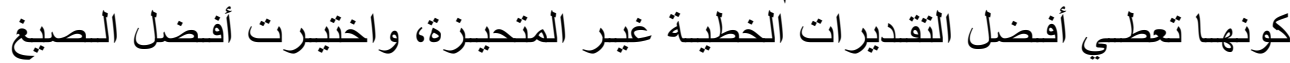
Goodness of Fit

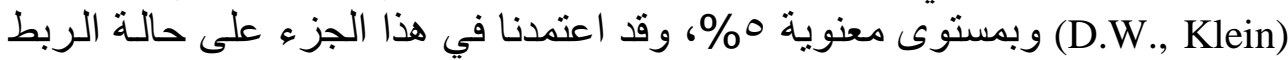

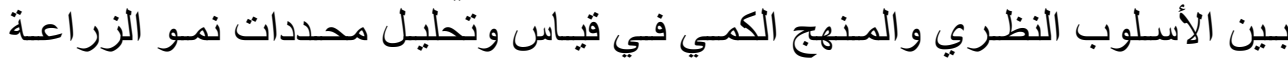

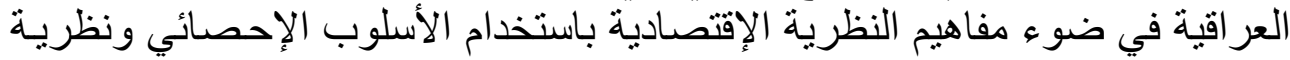
الإقتصاد القياسي في القياس و التحليل. وفيما يأتي تحليل المتغير ات المشار اليها آنفاً وتأثير ها في الناتج الزراعي على الئل وفق مفاهيم النظرية الإقتصادية.

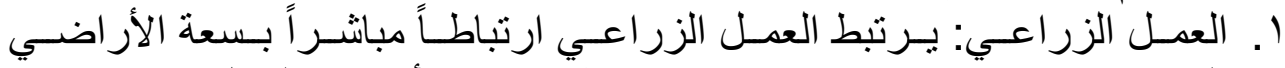

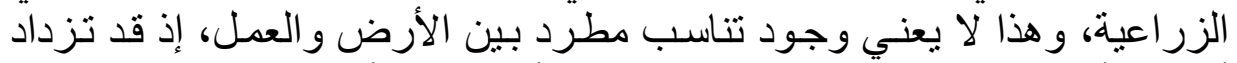

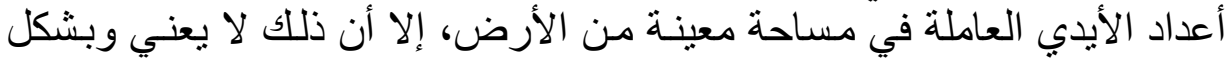

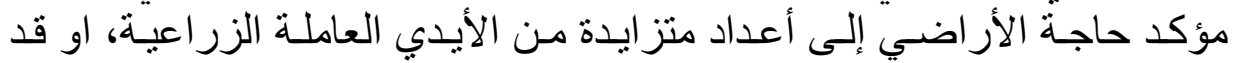

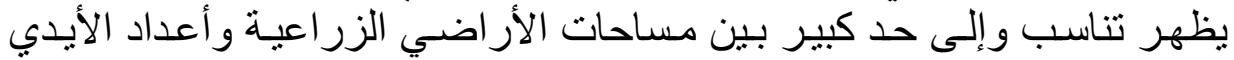

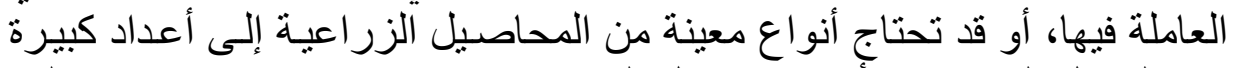

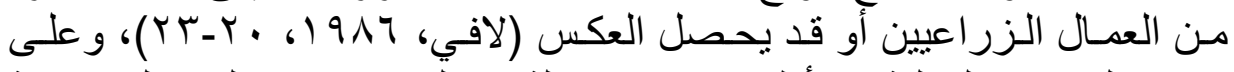

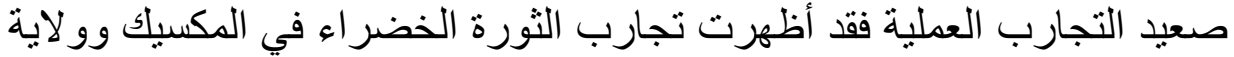

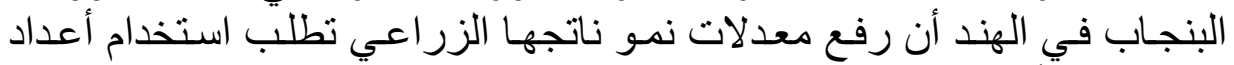

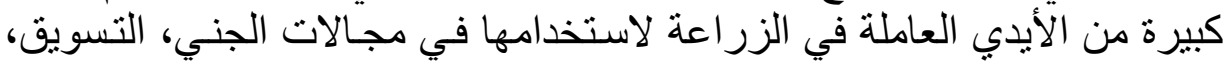

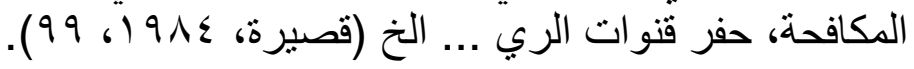




\section{دكتور غزال وعبد [rrr]}

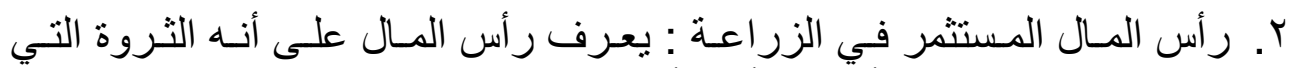

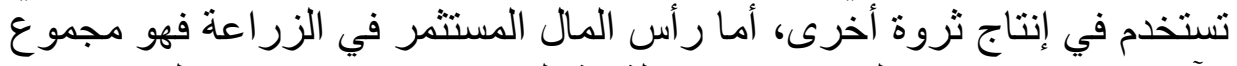

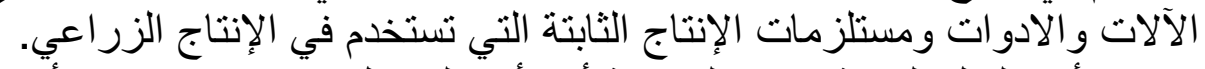

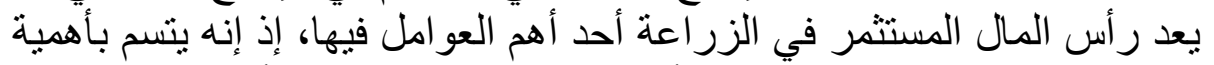

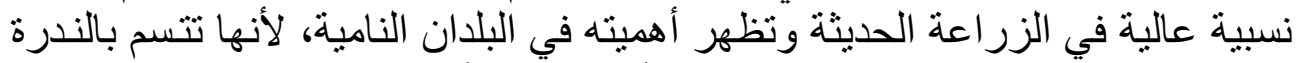

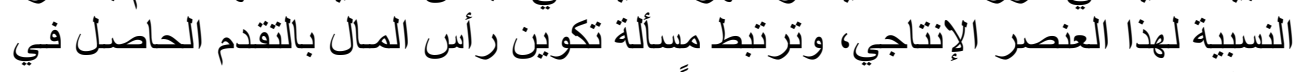

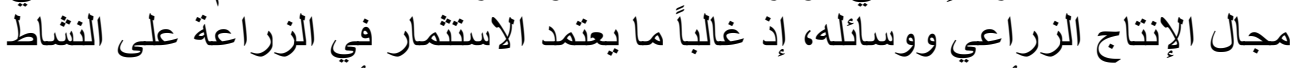

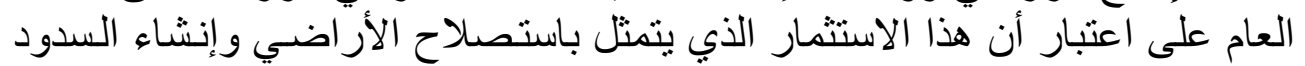

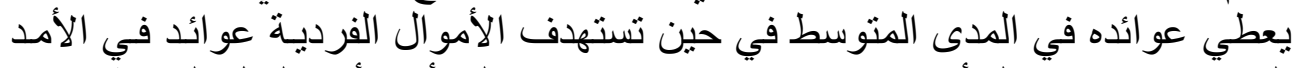

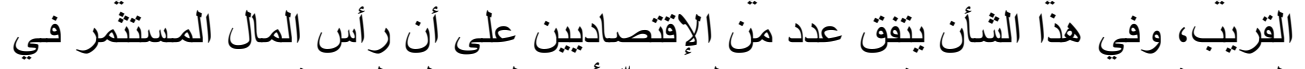

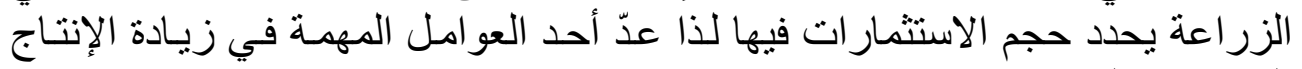

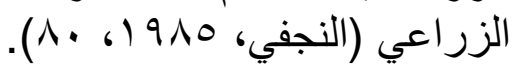

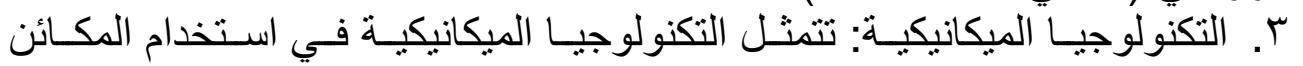

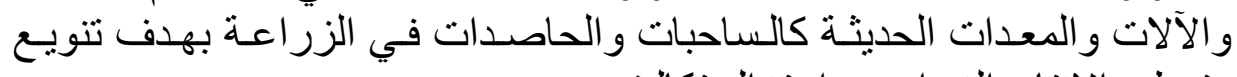

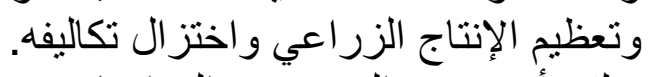

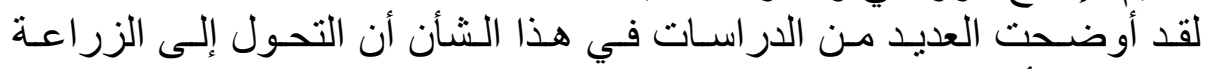

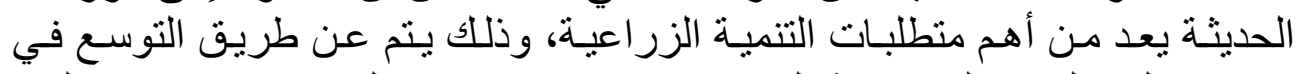

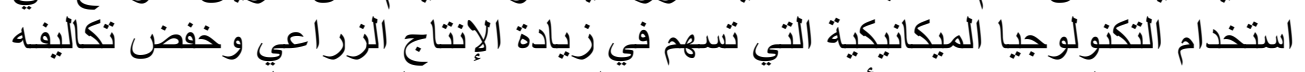

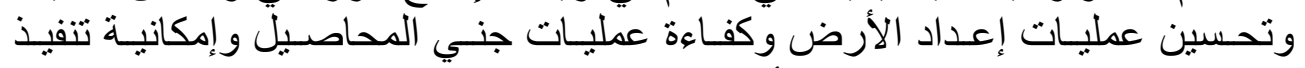

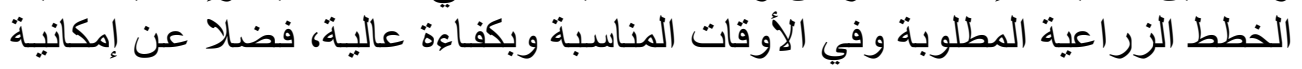

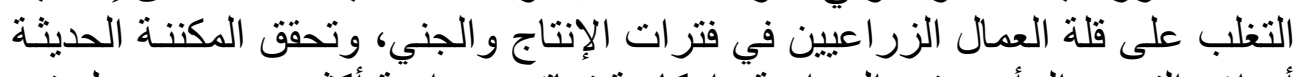

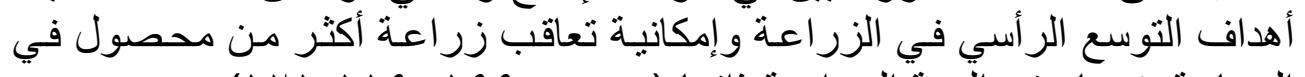

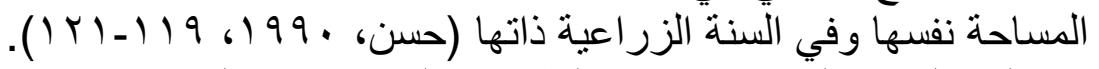

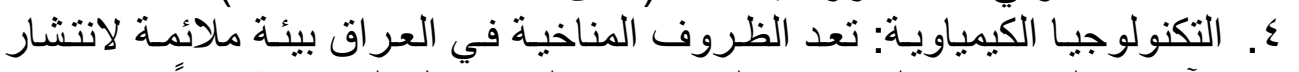

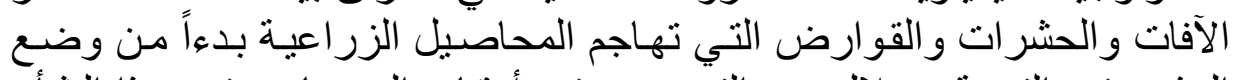

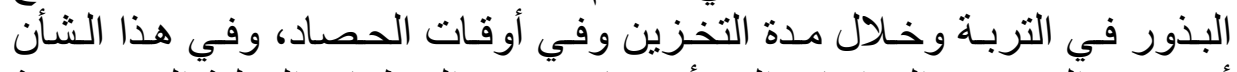

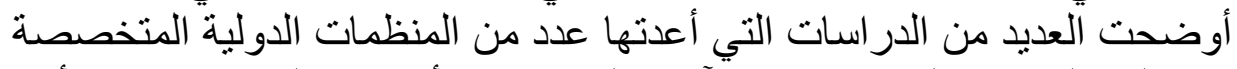

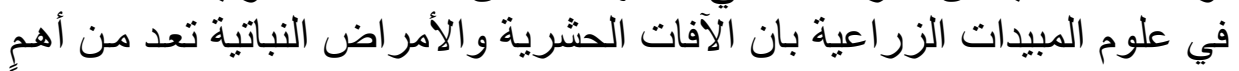

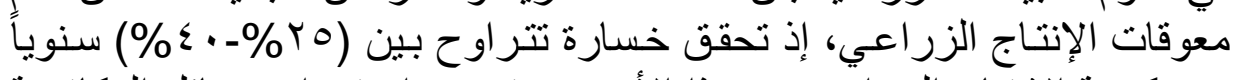

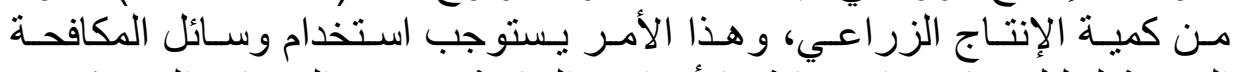

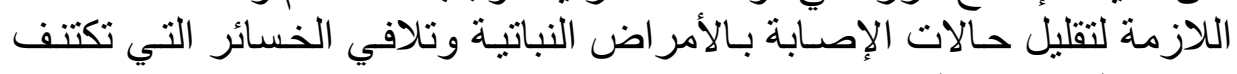

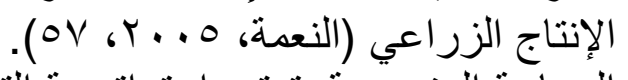

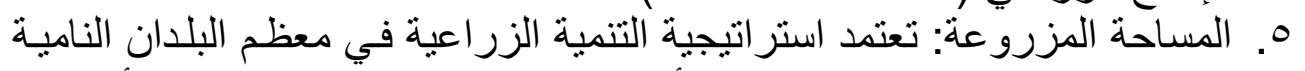

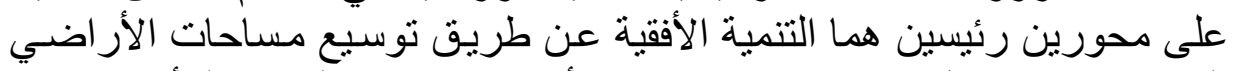

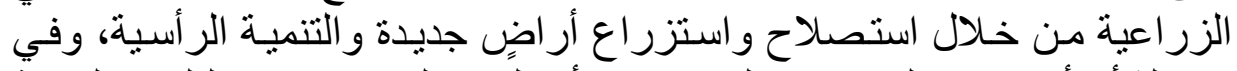

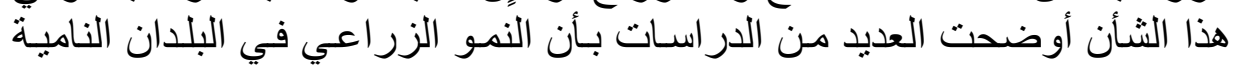


يعتمد وبدرجة كبيرة على توسيع المساحات المزروعـة، وذللك يسهر في زيـادة

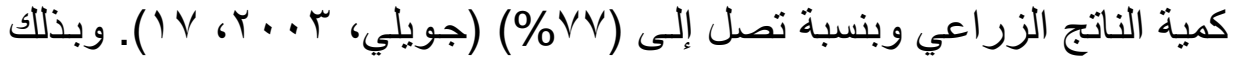

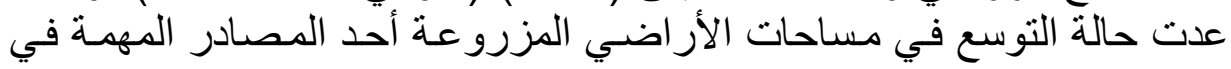

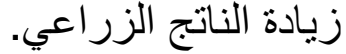

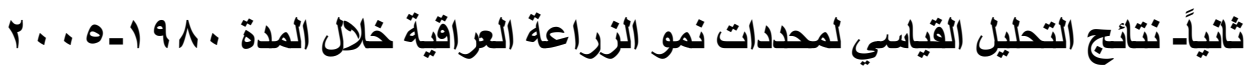

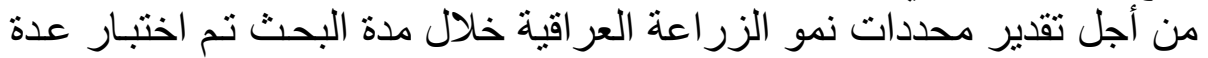

صيغ للتقدير وكانت الصيغة اللو غاريتمية المزدوجة قد أعطت أفضر أفضل النتائج الآتية: $\log y=-1.748+0.137 \log _{2}+0.338 \operatorname{Logx}_{3}+0.156 \log _{4}+0.479 \log _{5}$
$\mathrm{t}^{*}=$ $-(1.562)(1.817)$
(1.720)
(3.104)
(1.752)
$\overline{\mathrm{R}}^{2}=0.96$
$\mathrm{F}=157.877$
$\mathrm{D}-\mathrm{W}=1.406$

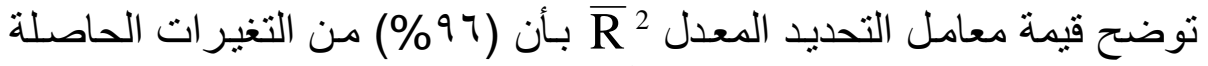

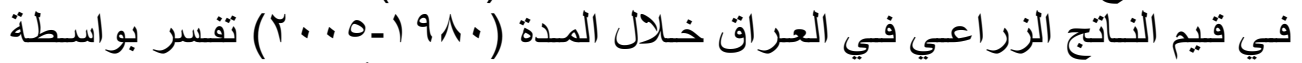

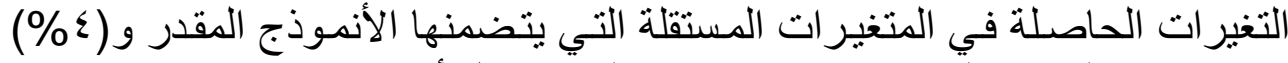

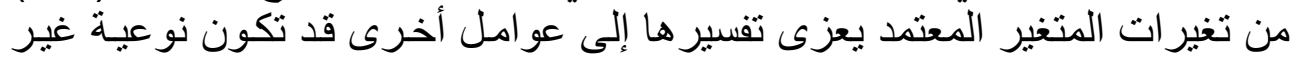

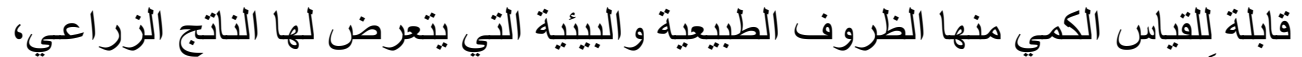

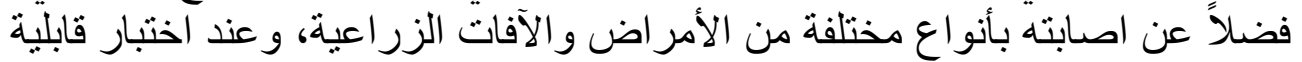

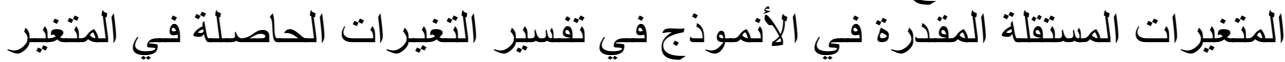

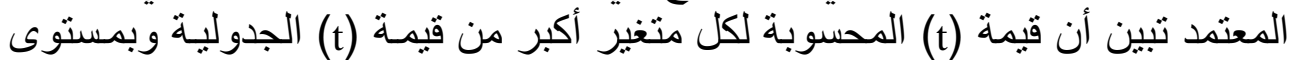

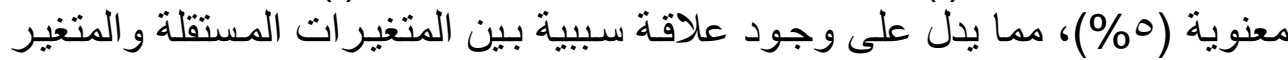

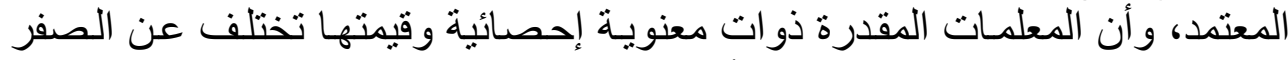

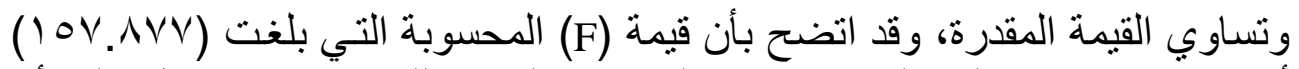

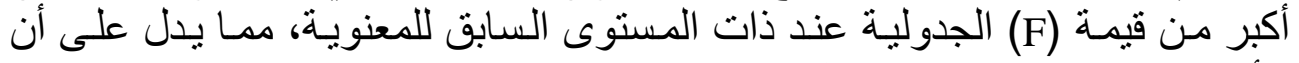

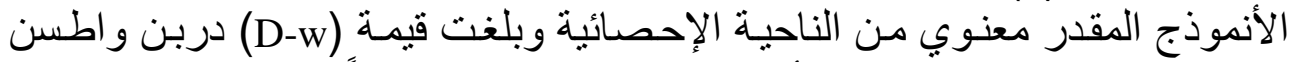

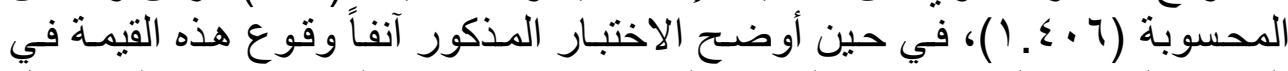

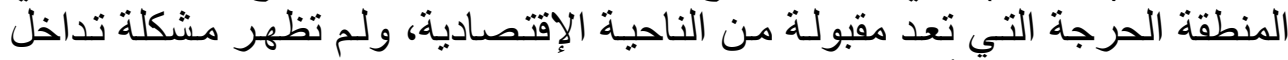

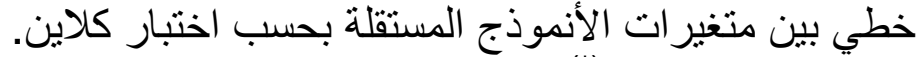

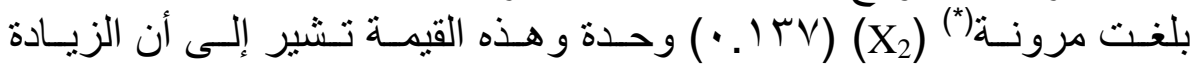

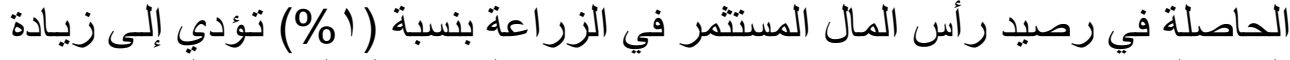

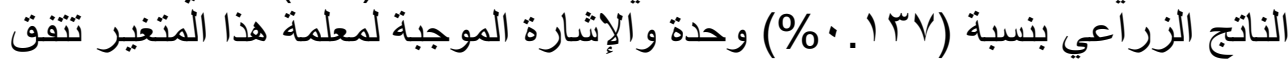

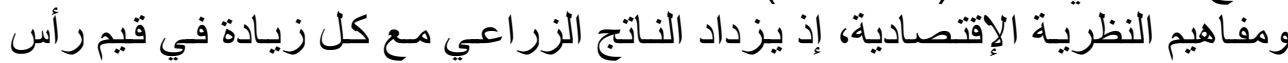

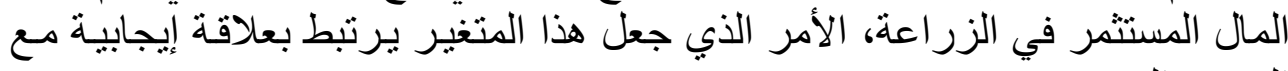

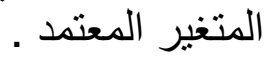

ep $=\beta \mathrm{i}$ 


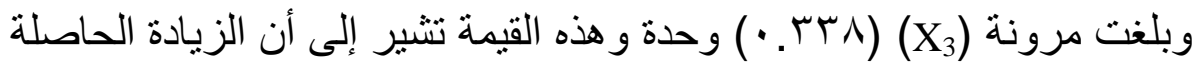

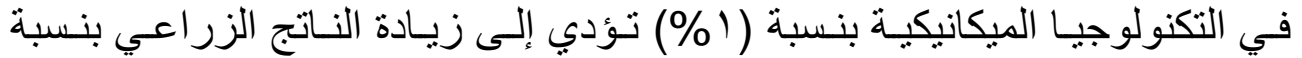

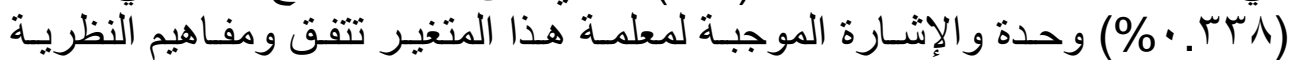

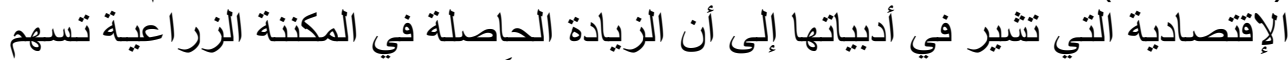

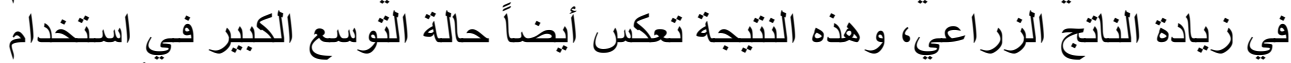

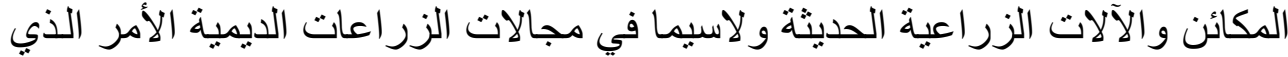

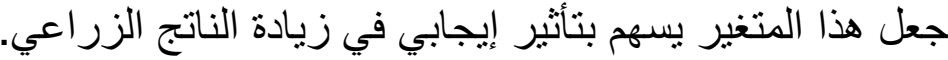

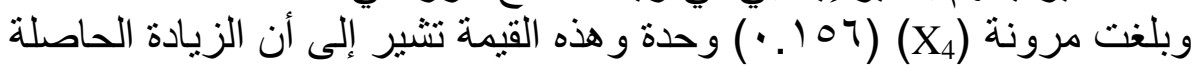

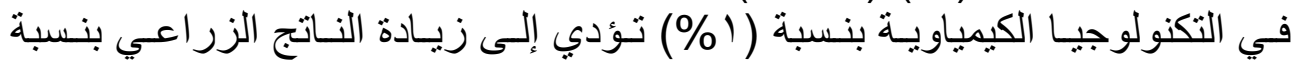

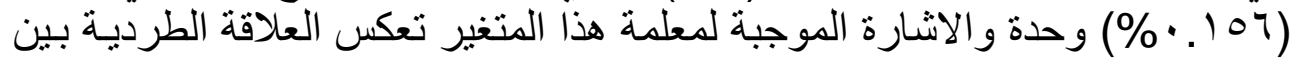

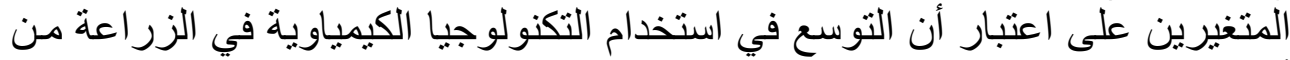

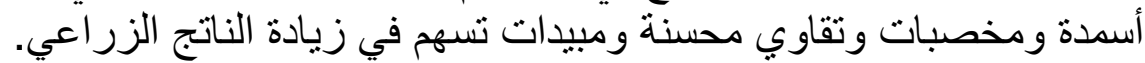

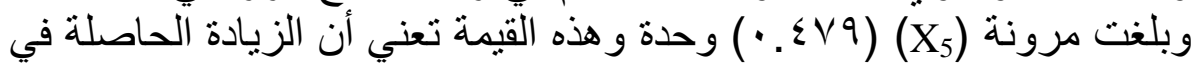

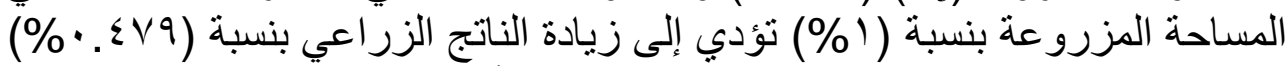

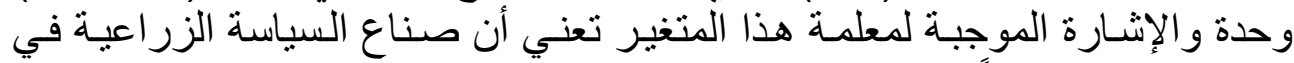

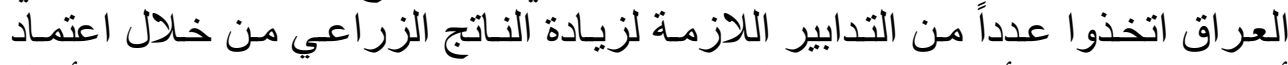

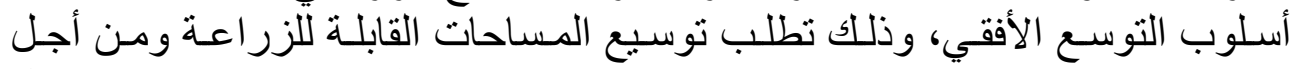

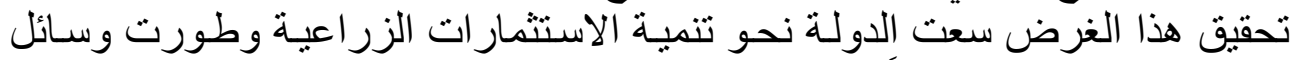

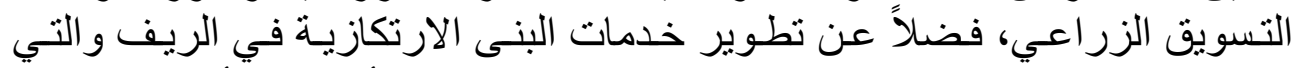

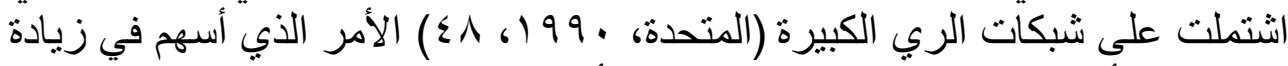

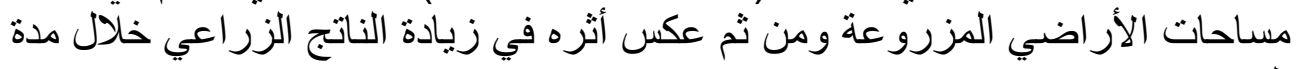
البحث.

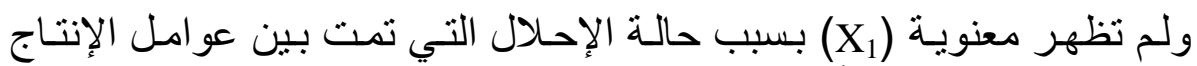

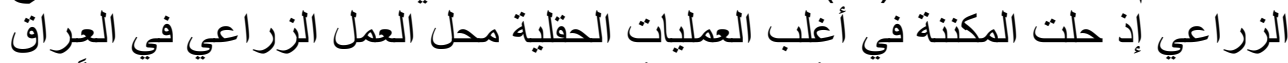

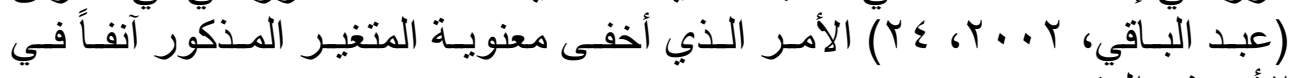

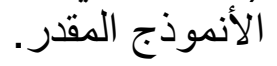




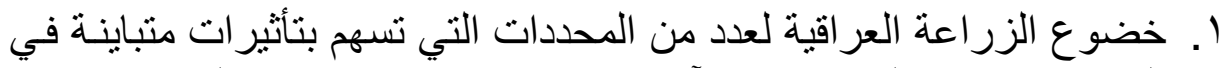

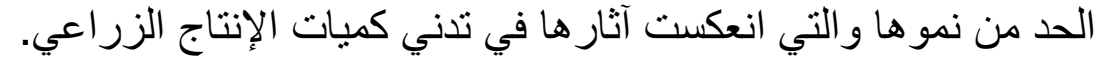

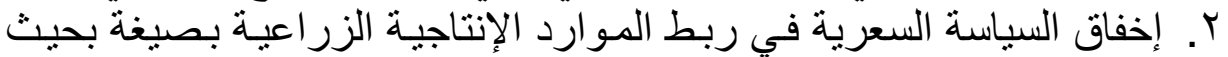

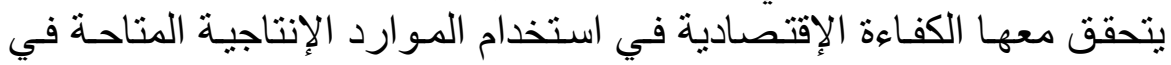
الزر اعة العر اقية.

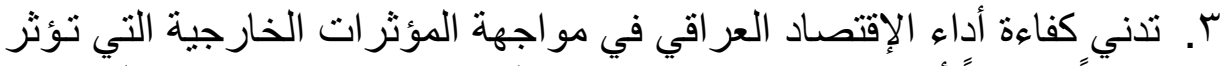

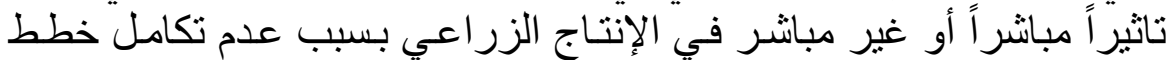

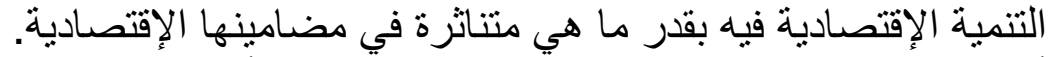

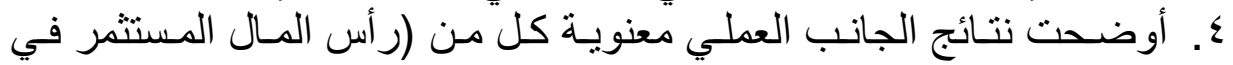

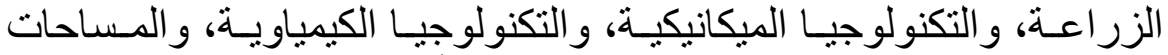

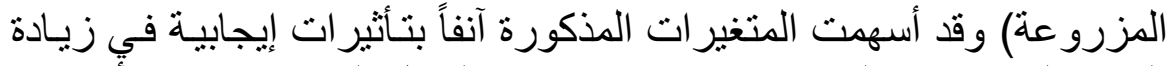

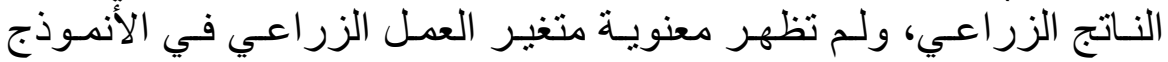
القياسي المقدر.

التوصيات ا. تبني سياسة زر اعية فعالة قادرة على معالجة أنواع العو امل كافة التي تعيق نمو

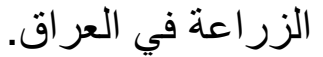

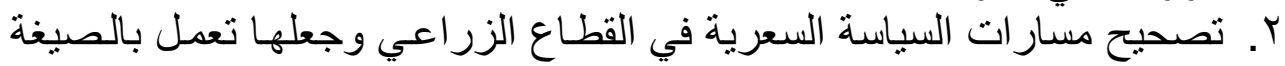

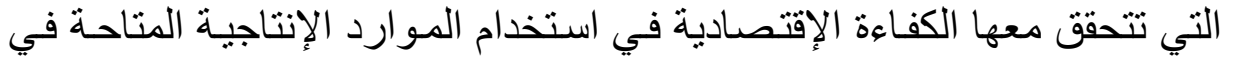

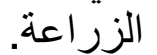

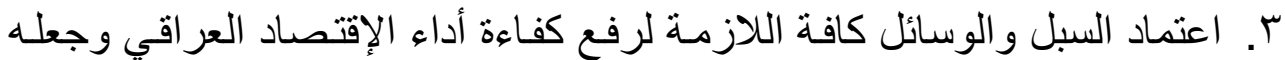

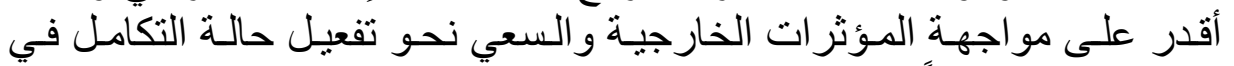
خططه التنموية بدلاً من جعلها المؤرات متناثرة.

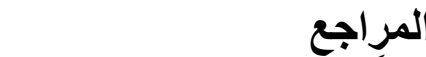

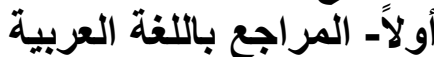

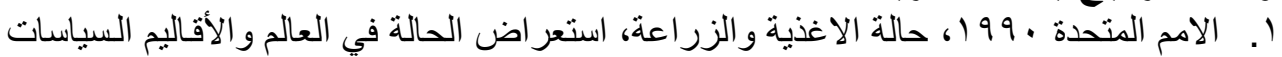

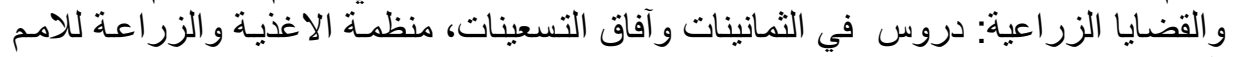

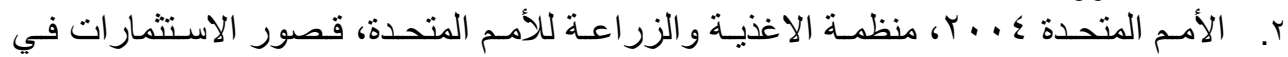

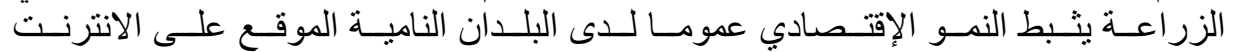
.www.alhage@ @ao.org.p2

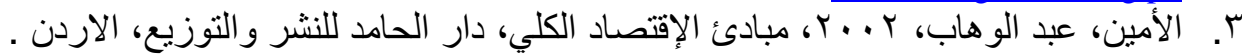

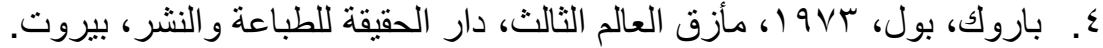

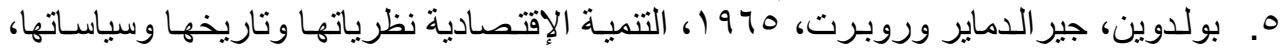

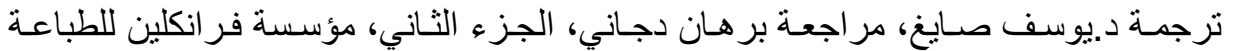




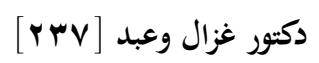

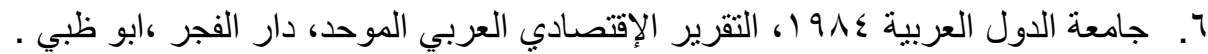

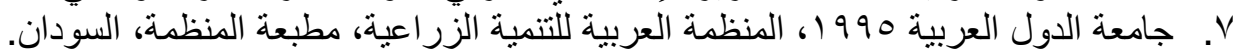

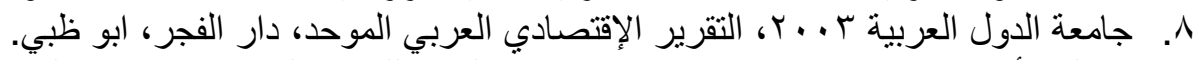

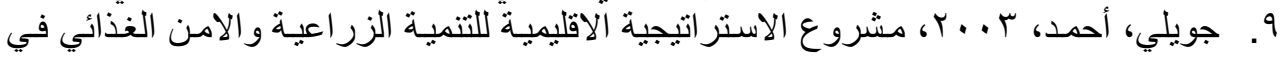

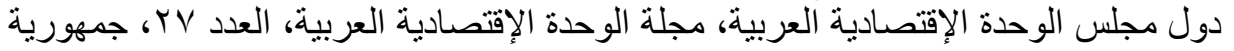

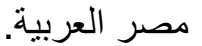

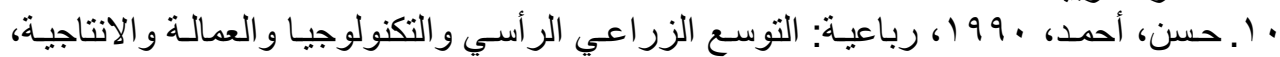

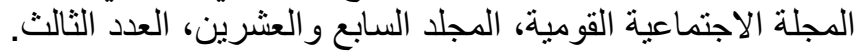

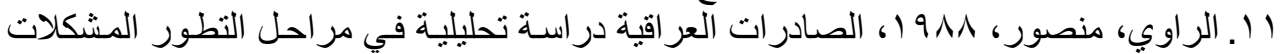

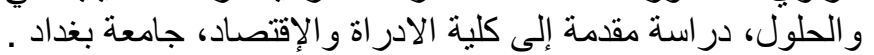

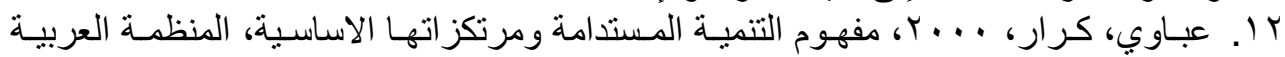

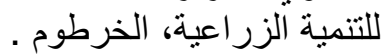

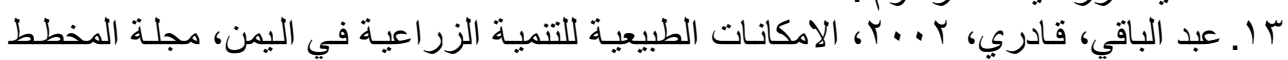

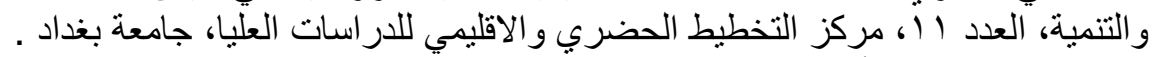

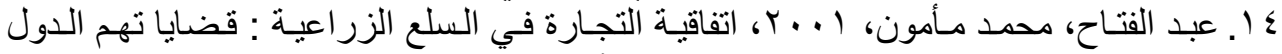

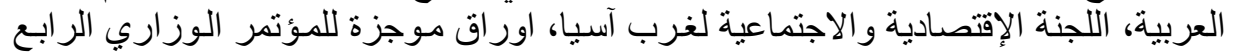

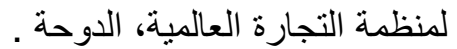

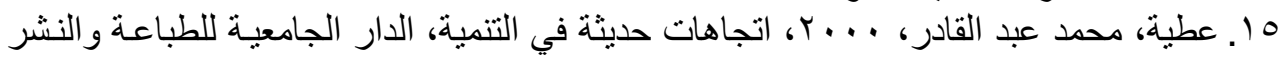
و التوزيع، الاسكندرية.

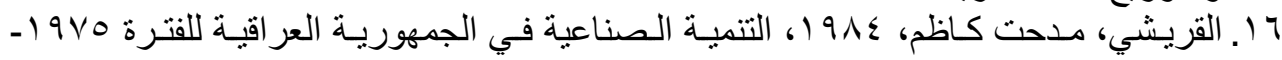

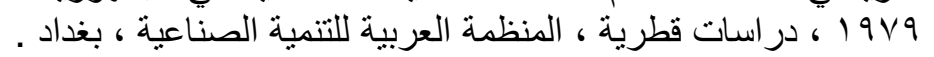

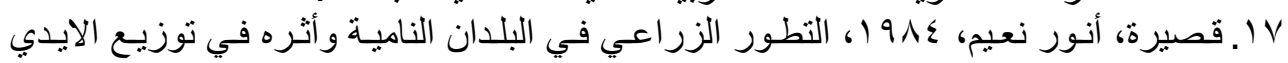

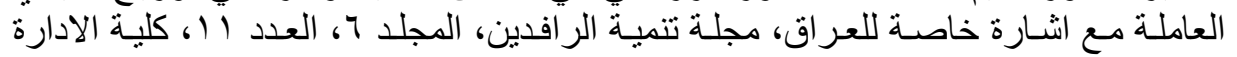

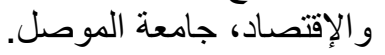

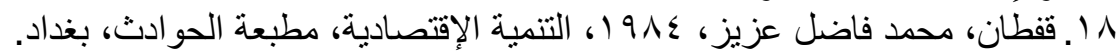

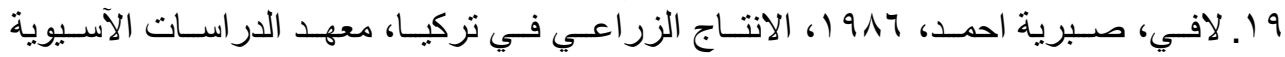

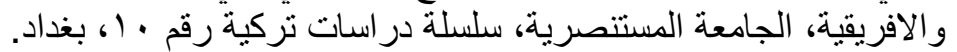

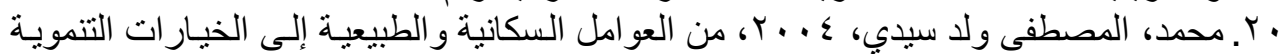

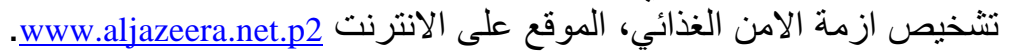

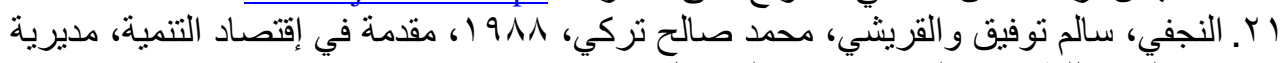

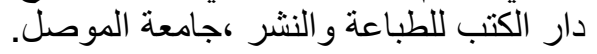

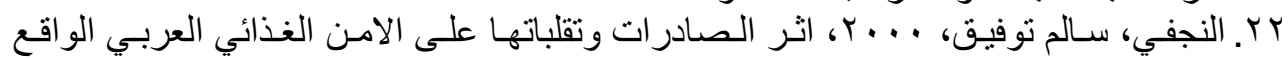

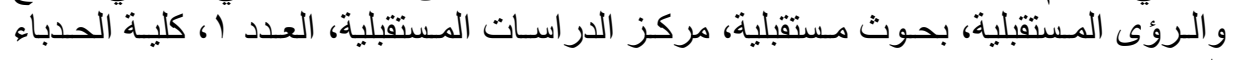

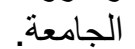

r r. النجفي، سالم، 1910 1، إقتصاديات الانتاج الزر اعي، مديرية مطبعة جامعة الموصل.

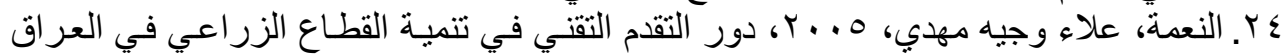

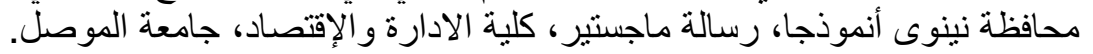

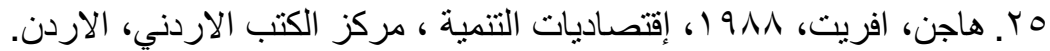

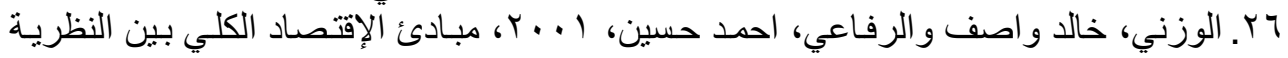
و التطبيق، دار و وائل للنشر، الاردن. 


\section{ثانياً- المراجع باللغة الاجنبية}

1. Thirlwall A.P. 1972, Growth and Development, Macmillan, London.

2. Mordechal E. Kreinim 1979, International Economics, Harcourt Brace Jouanovich, USA.

3. Stevens R.D. 1965, Rates of Growth in Food Requirement During Economic Development, Journal of Farm Economics, vol. 47, No5.

4. UNCTAD 1985, The Least Developed Countries Report, New York. 